\title{
Blurring time and place in higher education with bring your own device applications: a literature review
}

\author{
Marcus Sundgren $^{1}(\mathbb{D})$
}

Received: 2 November 2016 / Accepted: 12 January 2017 / Published online: 24 January 2017

(C) The Author(s) 2017. This article is published with open access at Springerlink.com

\begin{abstract}
The use of mobile devices is increasing rapidly in society, and student device ownership is becoming more or less ubiquitous in many parts of the world. This might be an under-utilised resource that could benefit the educational practices of institutions of higher education. This review examines 91 journal articles from 28 countries published in the years of 2009-2015 with regards to the applications of Bring Your Own Device (BYOD) in higher education to take inventory of how it is applied where blurring of boundaries of time and place can be observed, and to observe problems or obstacles regarding these applications. Research interests do not seem to shift, as much as they are becoming more diverse. The five applications that were identified in 2009 were in discussion during all of the examined years, whereas the total number of applications in discussion increased to 12 in 2015. A methodological concern with regard to trend analysis is that more than half of the articles lack a stated year of data collection. As this can differ greatly from the year of publication, any trend analysis will be burdened with uncertainty. That said, a pattern that emerges is a shift away from distribution of content towards social networking applications. Much less focus has been placed on obstacles and problems in later years, but some areas that have been addressed are usability problems due to small screens and keyboards, with costs of devices and data plans making ownership unfeasible for certain activity types or groups of students.
\end{abstract}

Keywords Bring your own device $\cdot$ BYOD $\cdot$ Higher education $\cdot$ Mobile learning $\cdot$ Place $\cdot$ Review. Time

Marcus Sundgren

marcus.sundgren@miun.se

1 Mid Sweden University, Holmgatan 10, 85170 Sundsvall, Sweden 


\section{Introduction}

Regardless of how we feel about it, the use of personal and portable devices is increasing rapidly in society. This in itself is not an argument for its adoption for learning in higher education, but strong indications exist that educational practice can benefit from activities blurring the boundaries of time and place (e.g. Berge and Muilenburg 2013; Miller and Doering 2014; Shippee and Keengwe 2014; Traxler and Kukulska-Hulme 2016). When speaking of blurring time and place, several convergences are denoted, like those between distance and campus education, formal and informal learning, private and public spaces, all leading to learners potentially taking control of their learning and students thinking together with less effort.

This review seeks to take inventory of technologies that have been studied and used in higher education settings with the support of Bring Your Own Device (BYOD) applications.

The use of the Internet at large has moved from interaction with content towards communication between people, and the ability to support and maintain communication beyond the classroom through technology is transforming educational experience (Garrison 2016) This is a trend that is further strengthened by the ubiquitous access to mobile technology for educational purposes enabled by BYOD practices. The term BYOD was originally coined in 2009 (Johnson et al. 2015) and refers to "the practice of people bringing their own laptops, tablets, smartphones, or other mobile devices with them to learning or work environments" (Johnson et al. 2016, p. 36). The key aspect of it here is that of ownership. The device is outside of the education provider's control, thus requiring special considerations for the design and delivery of learning materials, and for the type of interactions that can be required of students. A strong argument in favour of a BYOD philosophy is that an institution that decides to produce materials that are dependent on a specific brand of device will require students without this type of device to either purchase the specified device, or opt out. This type of requirement placed on the student is simply not fiscally realistic for most public institutions (Caudill 2007; Koole et al. 2010).

Higher education is often discussed in terms of campus-based or distance education, or maybe as a middle ground termed blended learning, where components of distance education are brought into campus education. Still, two distinct locations are traditionally assumed: the campus classroom and the student's home. This notion is being challenged by the mobility and accessibility of modern mobile devices, which makes opportunistic learning (Hedin 2014) feasible. Opportunistic learning is the utilisation of short, otherwise unproductive snippets of time, like when commuting, mowing the lawn, or waiting in line. This brings the potential of blurring the traditional boundaries of time and place in education. A leap in usability could be observed when the modern touchscreen smartphone was introduced in 2007 (Grønli et al. 2014), and continuous improvements in screen sizes and performance since then have been beneficial for user experiences (Pegrum 2014), further improving the chance of blurring time and place.

Consciously or not, the concept of BYOD imbues many studies. Applications of $\mathrm{BYOD}$ are closely related to mobile devices, and thus to mobile learning. The latter is a term that is concerned with aspects of learning, more than pertaining to an entirely new type of learning. Many early definitions were created in terms of its hardware and technologies, e.g. Keegan (2005): "mobile learning should be restricted to learning on 
devices which a lady can carry in her handbag or a gentleman can carry in his pocket" (p. 5). They are, however, "constraining, techno-centric and tied to current technological instantiations" (Traxler 2007, p. 4). Later definitions tend to emphasize communicative aspects, such as that by Pachler et al. (2010), which frames mobile learning as "the process of coming to know through [communication] across multiple contexts among people and personal interactive technologies" (pp. 6-7). For the purpose of this review, however, the only requirement is that the articles use the term "mobile learning" as a key concept.

A commonly promoted feature of mobile learning and BYOD that promotes blurring of boundaries is ubiquitous access and learning - the anytime, anyplace access to content. While easy information transmission has its advantages, a stronger case could be made for other models (Khaddage et al. 2015; Winters 2006), such as social connectedness with peers and teachers, as well as the added level of control and the possibility for self-regulated learning offered to the individual learner (Chayko 2008; Dron and Anderson 2014). The anytime, anyplace access is thus more about the learners being in control of the boundaries of time and place.

The above paragraphs are all examples of the blurring of historically rigid boundaries, and demonstrate why it is of importance in higher education settings. Thus, in summary, both general Internet use and definitions of mobile learning is moving away from a focus on content towards a focus on communication. Internet access has also become practically ubiquitous due to the rapid adoption of personal and privately owned mobile devices, making BYOD initiatives feasible on a larger scale. The improved usability of modern touchscreen devices compared to older feature phones (Pegrum 2014) might also have contributed to a shift in research focus, from the physical devices towards activities and possible uses these devices can support. These shifts in society at large raise the issue of whether the same trends can be discerned in the current research. Thus, this review sets out to explore the following research questions: How is BYOD applied in higher educational settings where blurring of boundaries of time and place can be observed? What problems or obstacles regarding these applications are observed?

This paper is structured as follows. First, some definitions of the technologies discussed are presented. In section 2 the research procedure and methodology is explained. Results at a general level are reported in section 3, examples of applications in section 4 , followed by obstacles or problems in section 5. Finally, conclusions are drawn in section 6 .

\subsection{Definitions of technologies discussed}

Some of the terms for technologies and applications that are discussed in this paper are sometimes used inconsistently; therefore a few quick definitions can be of value. A podcast (the word is a portmanteau of "iPod" and "broadcast") is an episodic series of digital audio files that a user can download automatically via web syndication to a local computer or portable media player, and unlike a radio broadcast it can be accessed anytime and anyplace, at the user's discretion. In this paper podcast strictly refers to audio recordings, and Vodcast (a portmanteau of "video" and "podcast") is used for the video equivalent. Video streaming is similar to vodcasts, but lacks subscription features and is typically referring to standalone recordings, and is often distributed via streaming 
services like YouTube. Social networking refers to "websites which support networking activities amongst friends, families and colleagues in a branded environment through communication, file sharing and information exchange" (MacDonald and Creanor 2010, p. 117). A blog, short for web log, is a web site allowing easy web publication of discrete, often informal diary-style entries (called "posts") that readers typically can comment on. A microblog is a cut-down version of a blog with a limited number of characters per post (typically 140-200). Posts can be displayed publicly on a website and/or distributed to private or public groups of subscribers. A wiki is a website that allows collaborative modification of its content and structure directly from the web browser, typically using a simplified mark-up language ('Wiki" 2016). A quickresponse code (QR code) is a type of matrix bar code that can be scanned with the camera of a mobile device that is equipped with a bar-code reader, e.g. a smartphone. It is typically used to store an Internet address for easy access.

\section{Procedure}

Although BYOD concepts are discussed in several studies, the term BYOD is seldom used to label them. This poses a challenge for any reviewer wishing to find as many papers as possible on the subject. As applications of BYOD are intimately connected with mobile devices and, hence, mobile learning (Johnson et al. 2016), the latter term has been used to maximize relevant returns from database searches. In this article, the term learning is used in its general, everyday meaning. However, in the presentation of results, terms for learning are being used as per the respective authors, leading to some sections signalling socio-cultural theories, whereas other segments signal cognitivist or constructivist theories for learning. This is intentional and is meant to indicate possible links between different applications of BYOD and different learning theories. A comprehensive search was conducted of the eight major online databases that $\mathrm{Wu}$ et al. (2012) used (ACM Digital Library, ERIC, Informaworld/Taylor \& Francis Online, JSTOR, ProQuest, SAGE, Science Direct Online, and Wiley Online). The search was performed with the keywords "mobile learning" and "higher education". Only journal articles published from 2009 through 2015 with the full texts available were retained. A thorough examination of the resulting list of journals revealed some omissions, and the following journals not covered by the databases were individually searched: American Journal of Distance Education, International Journal of Mobile and Blended Learning, International Journal of Mobile Learning and Organisation, Journal of Distance Education, ${ }^{1}$ and Open Learning. By examining abstracts, and by skimming the full texts in ambiguous cases, of the 380 articles matching the above criteria, 91 articles continued to meet the criteria of being concerned with higher education, BYOD, and the boundaries of time and place.

Coding of the full-text articles was conducted using a general inductive approach (Thomas 2006). To aid in this process, the qualitative data analysis software package Atlas. Ti was used for document and code management and analysis (Atlas.Ti 2015). The primary coding of the research themes was guided by the author-identified

\footnotetext{
${ }^{1}$ This journal changed its name to International Journal of E-Learning \& Distance Education in January 2015
} 
keywords from the articles, as well as by the analysis of the major implications for theory and practice reported in the conclusion sections, as demonstrated by Wickham et al. (2012).

A separate round of coding was performed with an attempt to determine the years of data collection. The difference between the year of publication and the year(s) of data collection was found to vary between zero and six years $(n=48, \bar{x}=2.1, \mathrm{~s}=1.2)$ for articles that did declare the year of data collection. This variation demonstrates the importance of using the year of data collection for any correlational analysis between technological generations/platforms and research themes to be valid.

\section{Results}

The 91 articles retained for analysis are distributed between years of publication according to Fig. 1. Previous reviews have observed a trend indicating an increase in the number of publications over time (Hwang and Tsai 2011). There appears to be an increasing number of publications year over year. This is supported by a regression analysis, showing a regression coefficient of 2.54 and an adjusted $R^{2}$ of 0.27 but the uneven distribution urges a cautionary interpretation of these values.

Out of the 91 articles, 86 are empirically oriented studies, three have a theoretic, and two have a method developing focus.

Of all of the articles, 48 explicitly stated the years of data collection. This leaves 43 articles (47\%) where years of data collection could not be determined (see Table 1). Data collected during 2007 or earlier can by necessity not be affected by smartphone use, as touchscreen smartphones did not gain market impact until 2008 (first iPhone released mid-year 2007, first Android phone fall 2008). When comparing data collection with the year of publication, 2012 was the first year without articles collecting data in the pre-smartphone era.

The geographical distribution of the articles, based on the first author's affiliation (see Table 2), is heavily skewed towards English-speaking countries with the most publications coming from the United States of America (USA) (15 articles), followed

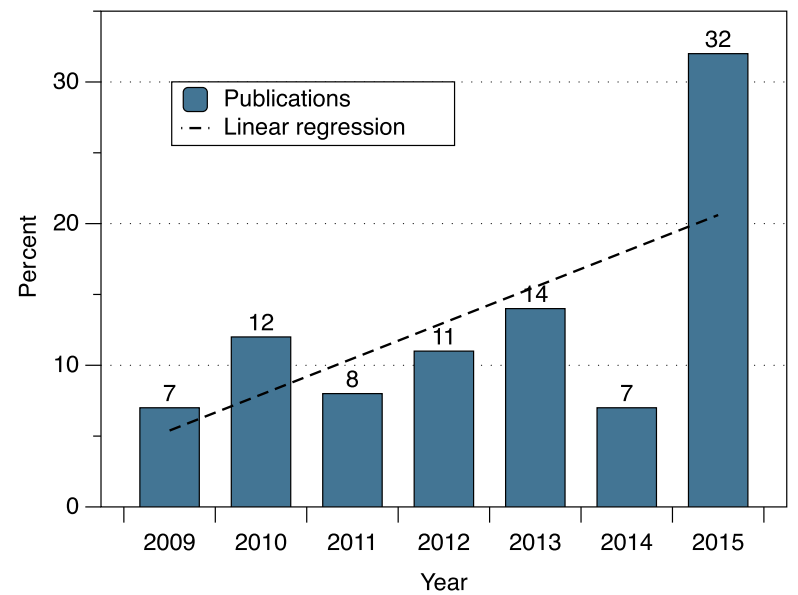

Fig. 1 Publications per reviewed year 
Table 1 Articles per era of data collection

Pre-smartphone era (2007 and earlier)

by the United Kingdom (UK) (12), Australia (12), South Africa and Taiwan (both 7). Europe accounts for 28 publications, Asia 25, North America 18, Oceania 13 and Africa 7. Worth noting is that all African publications have a South African affiliation, and that South America lacks affiliated first authors altogether.

A condensed summary of all articles in this review can be found in the appendix Table 5. The summary includes (a) author names, (b) article title, (c) publication year, (d) stated year(s) of data collection, (e) country affiliation of the article's first author, (f) types of respondents and $(\mathrm{g})$ stated purpose of the articles.

\section{Examples of how BYOD is applied}

Some research suggests that the use of mobile devices can challenge traditional interpretations of place, for instance what constitutes a public and a private place. Bradley and Holley (2011) finds that "mobile devices are reconfiguring the relationships between public and private spaces" (p. 50) as they give students greater flexibility in choosing places for learning. An illustration of this blurring of place is the observation by Ilic (2015) where mobile devices allowed students to create a private space even in public places, such as on a crowded train, and that the "role of the smartphone as an essential communication tool and its ability to switch effortlessly between the private websites and the public homework site places the device as a bridge between public and private life" (Ilic 2015, p. 29). The dominating application of BYOD is the use of various social media and communication technologies. In Table 3 the number of

Table 2 Articles per first author country affiliation

\begin{tabular}{ll}
\hline Country & Articles per \\
& country (total) \\
\hline USA & 15 \\
UK & 12 \\
Australia & 12 \\
South Africa & 7 \\
Taiwan & 7 \\
Germany & 4 \\
Canada, Malaysia & $3(6)$ \\
Iran, Israel, Jordan, Oman, Serbia, Spain, Switzerland, United Arab Emirates & $2(16)$ \\
Belgium, Finland, Greece, Hong Kong, Ireland, Japan, Netherlands, New Zealand, & $1(12)$ \\
$\quad$ Saudi Arabia, Singapore, South Korea, Turkey & \\
Total & 91 \\
\hline
\end{tabular}


Table 3 Articles mentioning application per year of publication

\begin{tabular}{|c|c|c|c|c|c|c|c|c|}
\hline & Year & & & & & & & \\
\hline Application & 2009 & 2010 & 2011 & 2012 & 2013 & 2014 & 2015 & Total \\
\hline LMS & 2 & 3 & 4 & 5 & 9 & 4 & 14 & 41 \\
\hline SMS & 4 & 7 & 3 & 2 & 7 & 3 & 8 & 34 \\
\hline Podcasting & 4 & 4 & 3 & 5 & 7 & 2 & 8 & 33 \\
\hline Social Networking & & 2 & 3 & 4 & 7 & 2 & 14 & 32 \\
\hline Instant Messaging & 3 & 4 & 3 & 1 & 7 & 3 & 9 & 30 \\
\hline Blogging & 1 & 2 & 2 & 3 & 5 & 4 & 9 & 26 \\
\hline Facebook & & 2 & 3 & 3 & 6 & 2 & 8 & 24 \\
\hline Microblogging & & 1 & 2 & 2 & 4 & 2 & 8 & 19 \\
\hline Wiki & & & 1 & 1 & 1 & 1 & 9 & 13 \\
\hline QR & & & & & 1 & 1 & 4 & 6 \\
\hline $3 \mathrm{D}$ & & & & & & & 4 & 4 \\
\hline Augmented Reality & & & & & 1 & & 2 & 3 \\
\hline
\end{tabular}

articles mentioning various popular applications of BYOD is listed in order of occurrences. Note that the presence of a topic in an article does not mean it is the focus of the article's empirical examinations.

The occurrence of sentences in an article mentioning the subject in question can vary from 1 to nearly 200. It is therefore obvious that the above method does not reflect the extent to which a certain subject was discussed. To better estimate the amount of interest in a certain application, the number of sentences mentioning it has been counted. In Fig. 2 the percentage of sentences containing these subjects per year is displayed. This aids in painting a picture of how interest in different areas changes over time. As the number of publications per year varies greatly, frequencies are less suitable for comparison.

Some observations can be made from this. The number of different applications discussed increases year over year, starting with five in 2009 and increasing to twelve in 2015 (Fig. 2). The most common application in these articles is podcasting, drawing a fairly even amount of interest over time. Also, interest in the early applications has not decreased substantially as other applications appear; new applications are just added to the palette. One possible exception is text messaging. There is a tendency that interest is shifting away from short message service (SMS) towards instant messaging (IM). SMS and IM applications are similar in function, but the latter has higher requirements for Internet access and access to app-capable devices, possibly reflecting improving device standards among students. Social networking applications are generally on the rise, such as Facebook, microblogging and instant messaging. Two applications entered in 2015, 3-D and augmented reality (AR). As both require high performing graphics this indicates that some critical performance threshold for mobile devices have been reached.

A similar analysis as above was performed regarding perspectives on learning. The occurrence of sentences mentioning constructivism and socio-cultural perspectives was counted and the results are reported (see Table 4) for two periods, 2009-2011 that contains articles collecting data in the pre-smartphone era (Table 1) and 2012-2015 that does not contain articles stating data collection in that era. 


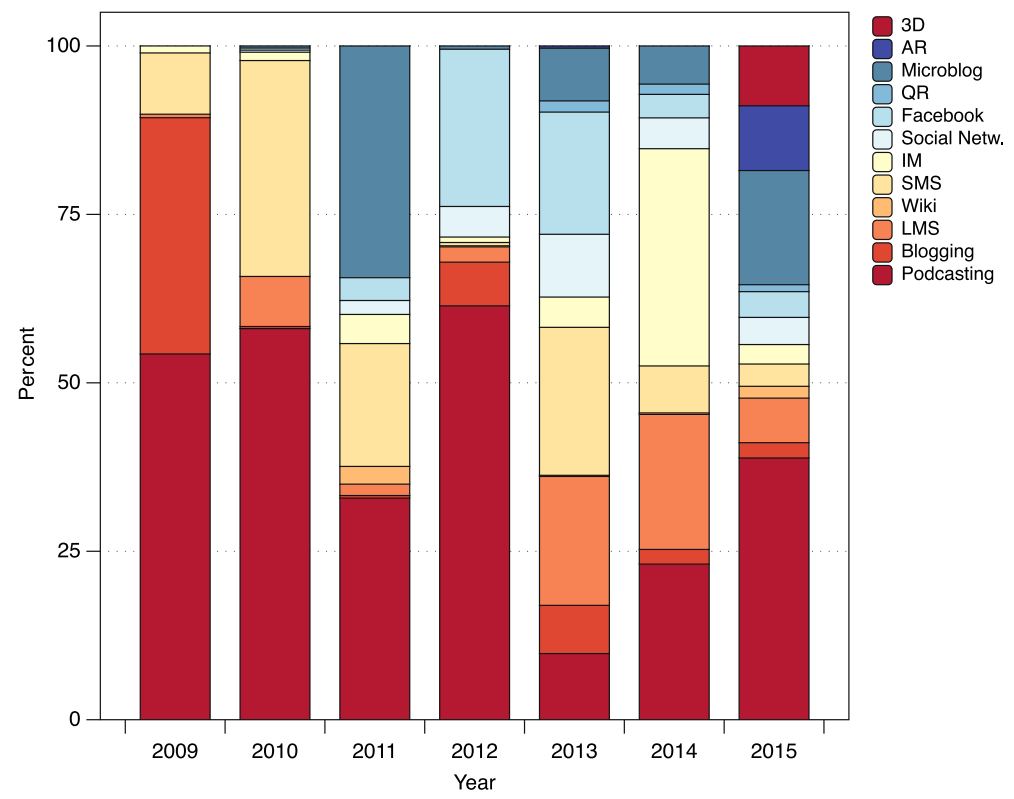

Fig. 2 Sentences mentioning specific applications, in per cent of occurring sentences per year

There is no mention of socio-cultural perspectives in the first time period, only in the second. The numbers above indicate that interest in constructivist and socio-cultural perspectives are increasing over time.

\subsection{Podcasting}

Podcasting is the most thoroughly studied application of BYOD, with 33 articles mentioning the term and 24 articles having it as the primary focus and examining its use in a wide selection of academic subjects. Interest in this area was relatively constant during the period of study. Ng'ambi and Lombe (2012) proposed a classification scheme for podcast types, where the four podcast types are: a) replicating lectures, b) supplementing lectures, c) replacing lectures, and d) student produced podcasts. The time- and place-shifting of lectures is the dominating example in the reviewed articles, e.g. podcasts of type "a". A few studies deal with podcasts of type "b", and one study is of type "d", but none of the examined empirical studies examined is of type "c". The first category "a" can be further subdivided into direct recordings of lectures, and summaries of lectures recorded at separate occasions. The first subtype has the

Table 4 Number of articles and number of sentences containing constructivist or socio-cultural perspectives for pre-smartphone era articles and smartphone era articles respectively

\begin{tabular}{llll}
\hline Publ. Years (n) & Articles & Sentences & Per cent of Articles \\
\hline $2009-2011(27)$ & 4 & 7 & $15 \%$ \\
$2012-2015(65)$ & 26 & 114 & $40 \%$ \\
Total (92) & 30 & 121 & $33 \%$ \\
\hline
\end{tabular}


advantage that it takes almost no extra time for the teacher to produce, but the pace of the recording is often poorly suited for listening as the teacher naturally focuses on the live audience, and sound quality can be lacking. The second type has the advantage of being better adapted to the distribution form, usually being better paced and of higher audio quality. A disadvantage is that it consumes a lot more teacher time in terms of preparation, actual recording time and post-recording editing. An interesting variety of type " $b$ " is primer podcasts, approximately five-minute recordings that each consist of an introduction to theories and summary definitions of core concepts from the upcoming lecture, ended with epistemic questions meant to stimulate deeper learning. Popova, Kirschner and Joiner's study (Popova et al. 2014) found positive effects on student engagement with this intervention, although no change in learning outcomes could be observed. Pegrum et al. (2015) examined student-produced podcasts (type "d") and found positive learning outcomes for some of the tasks. They concluded that, as there were no negative effects from student creation of podcasts, instructors should be encouraged to consider adopting creative approaches. Several reasons have been given for why podcasts would augment the teaching and learning practice. One is the supposition that podcasts can be used to take advantage of otherwise unproductive snippets of time, so-called opportunistic learning (Hedin 2014). With podcasts and portable technology it could be possible to access course material during commuting, while gardening, when training etc.:

podcasting is commonly seen as a way of supporting m-learning since it enables learners to access course material on portable devices in any location. This opens up possibilities of accessing the material at opportune times such as during commuting. (McGarr 2009, p. 318)

The reasons mentioned for time- and place-shifting lectures through podcasts are potentially better retention through the possibility of repetition, and handing more control of the learning process over to students. The continuing interest in researching podcasting might be somewhat surprising, since there exists a perception in the research community that this is a technology that is becoming out-dated (Sundgren and Jaldemark 2016).

\subsection{Social networking}

The second most researched application of BYOD is social networking, with Facebook being the most common platform used. The publication dates for articles concerning social networking are distinctly skewed towards later years. A typical example of a studied area is a social networking site (usually Facebook) used as a platform for communication between faculty and students as well as between students only. The latter includes the exchange of learning material (de Waard et al. 2012) and the facilitation of group work (Bradley and Holley 2011). This in some respects replicates the functionality of a learning management system (LMS). There have also been examples of social networking uses occurring among students that were not initiated or explicitly encouraged by the educational institution. For instance, informal learning clusters "often merged discursive practices like tweeting, Facebooking, and general communications to ensure more enriched social practices" (Rambe 2012, p. 55). In 
another example, a group of students started a Facebook group for exchange of work and ideas just before a holiday. Due to volcanic ash's affecting the European airspace, some students were unable to return in time for the completion of a group assignment but could continue to participate in the Facebook group to finish the project: "[w]hat was started as a means of communicating turned into a 'life saver' for these students" (Bradley and Holley 2011, p. 47). A less common example is students accessing an expanded community of external professionals in their subject area, as in Pimmer et al. (2012) case study of medical education where many students participated in Facebook groups dedicated to medical education purposes.

\subsection{Text messaging}

Text messaging, or SMS communication, is the focus of eleven articles. The distribution of articles over time is fairly uniform, with a possible drop in the last year. Examples of use range from administrative access and support, to formative assessment, collaborative learning tasks, and teacher guidance. Young et al. (2010) used SMS as a means of providing support to health students while in practice placements. They found that students experienced an enhanced sense of support with this system in place, even the students who did not use it:

"The fact that texting enhances a sense of support even where students do not use it make the facility very attractive. It can be seen a means of enhancing students' experience on placements with very low costs to the University in terms of finance and staff energy" (Young et al. 2010, p. 123).

Opportunistic and bite-sized learning via text messaging was tested in English learning in two different studies. One compared the learning of English idioms through classroom instruction, self-studies, and SMS distribution. Four idioms were sent per day in three-hour intervals. The SMS treatment group was found to have significantly higher learning outcomes (Hayati et al. 2013). A similar study using SMS to teach English vocabulary via the SMSdistribution of English words and definitions every 30 min during office hours also reported positive learning results, although no control group was part of the research design (Cavus and Ibrahim 2009). Morris (2010) combined podcasts with formative feedback via SMS. Each podcast episode contained five multiple-choice questions. Students responded to a question by sending a specific code in a text message, generating an automated response. Students using the podcasts and mobile formative assessments experienced a significant improvement in examination performance.

\subsection{Blogging}

Blogging has a relatively long history of use in education. With this background it is somewhat surprising that most articles were published in the latter half of the studied period - eight articles compared to one article in the first half - but this might be a result of improved usability on mobile devices for content production. Some blog implementations were motivated by the possibility of 
facilitating opportunistic learning. Vuojärvi et al. (2012) implemented learning diaries for students during their apprenticeship period. With mobile access to blogs, students could take advantage of breaks or periods of waiting for customers. Another take on the opportunistic learning is the use of blogs for medical students posting questions and asking for assistance on subjects or situations encountered while treating patients, thus placing emphasis on student-to-student communication (Wilson and Bolliger 2013). A similar argument for blogging is the support for situated learning it could provide. Gikas and Grant reported on the affordance of mobile devices in combination with blogs, making it possible for students "to collect data and interact with content as they immediately came across it in their daily lives" (Gikas and Grant 2013, p. 22). Students perceived blogging as promoting meaningfulness and as linking instructional content and authentic contexts in important ways. Most examples were of student use, but one example of blogs was for faculty use. In this case, the blog was employed for information exchange within a teacher community of practice (Cochrane et al. 2013). This study also found that a blog as a reflective student discussion area benefited students who otherwise were reserved in face-to-face debate and that it helped students to discover beliefs and motivations of others. To conclude, this technology is making its way onto the mobile platform, demonstrating that production of content, and not just consumption of content, can be viable on mobile devices in spite of their small screens and keyboards.

\subsection{Microblogging}

Microblogging is a service influenced by the ubiquitous access to SMS messaging via mobile phones, as well as the distribution model of Internet Relay Chat (IRC) and its status messages. The dominant platform is Twitter and that is also the only microblogging platform examined in the reviewed articles. Academic applications of Twitter range from use as a channel for administrative announcements in a library context (Cassidy et al. 2014), as a virtual community building tool (Cochrane et al. 2013), for sharing content between students (de Waard et al. 2012; Rambe 2013), to gain access to an extended community and interact directly with subject matter experts (Gikas and Grant 2013), and as a communication platform (Rambe 2012). Tweeting is furthermore, under the right circumstances, assumed to help improve social presence and to stimulate the students' desire to learn (Menkhoff et al. 2015). In conclusion, although microblogging can appear to be a one-way distribution channel for content, it could be implemented to support aspects of the Community of Inquiry model (Garrison 2017; Garrison et al. 1999) to improve both social and teaching presence.

\subsection{Instant messaging}

Several providers/platforms exist for instant messaging services. Allagui (2014) examined whether using the WhatsApp platform in English learning could improve students' motivation to write, and a positive effect on motivation could be established. Other effects were that vocabulary and spelling skills in language classes improved, but grammar, idea development, and organisation were lacking. In Antonenko et al. (2013)study of attitudes towards mobile LMS 
features, females were significantly more inclined to find instant messaging features useful, and students in general perceived instant messaging to be more important than what faculty did. Because many different services are coming together in a single device, the blurring of boundaries between them is starting to emerge. SMS and instant messaging are becoming less and less distinct, which might lead to SMS becoming an outdated form of communication (Brett 2011). Similarly, traditionally computer-based tasks, such as instant messaging, are showing a large increase in use on phones (Cassidy et al. 2014).

\subsection{Video streaming}

Video streaming refers to videos made available to students online, typically via video sharing sites such as Youtube, or directly through an LMS, What separates video streaming from vodcasts (video podcasts) is that the videos can be accessed directly, without the need for subscribing to feeds. Some concern has been raised that recorded lectures might lead to decreased attendance in class (McGarr 2009). An experiment with video vignettes as a preparatory tool for practical classes, however, led to an increase in attendance and an improvement in the perception of the relevance of the subject for students' future professions (Ernst et al. 2012). Another critique against video lectures is their unidirectionality, not lending themselves to communication and dialogue. By supplementing videos with a commenting function through the development of a platform (MOBILect) this problem was addressed in two studies (Boyinbode et al. 2013; Boyinbode and Ng'ambi 2015). The results indicated that this tool encouraged students to ask questions they would not dare to ask in class, benefited shy students, and allowed students to gain a deeper understanding of the lecture by exposing them to other people's ideas and opinions. Sadik (2015) investigated student preferences for video lecture formats. Comparing full-length lecture captures with supplemental and shorter screencasts covering the same subjects, students were found to be in favour of the latter format.

\subsection{QR codes}

Quick Response (QR) codes are intimately associated with modern smartphones, as they depend on three key features: a camera to scan the code, a live Internet connection, and an app to process it. Still, only six articles mention QR codes. This could be because the code is a same-place technology-physical presence at the same location as the QR code is a requirement for scanning it - and therefore it might not be of interest in scenarios exploring flexible place. Furthermore, Cassidy et al. (2014) found that students reported low familiarity with QR codes as a concept, and those familiar with it used it quite infrequently, not matching the recent hype surrounding the technology in the library science field. Cochrane et al. (2013) explored QR codes in a journalism course, with the initial student response that it was a "gimmick", but after some exercises raising awareness about QR code use in local news publications, students started to explore its potential. Yin and Fitzgerald (2015) did see 
positive attitudes towards the use of QR codes, but it was mostly used to simplify a login process.

\subsection{Wiki}

Wikis were discussed in two articles, but just one treated the subject with any detail. In that article, students were required to use a wiki for a group assignment where participants could be in different time zones. The benefits that were mentioned for using a wiki were twofold, the most obvious being the ability of students to work at a time and place of their convenience (Soon 2011; Wilson and Bolliger 2013). The second benefit was the teacher's ability to track and follow individual students' contributions to the assignment through the wiki's history feature: "Wiki's history helped the instructor to monitor both the students' activity and their levels of contribution to the project and therefore made the assessment of individual members easier" (Soon 2011, p. 49). Students were mostly positive towards using the wiki, but many were not familiar with how to use it, and a majority "described a need for more time for Wiki training before embarking on their required group assignments" (Soon 2011, p. 47). The functionality described above can also be found in collaborative office suites online, such as Google Drive/Docs and Microsoft Office 360. As usage of these services does not require as much specialized knowledge, it is likely that they will replace wikis to some extent in the future.

\subsection{LMSs and mobile access}

Mobile LMS access seems to be increasing, as exemplified by data from New Zealand where mobile access quadrupled during the last year of the study (Ernst et al. 2013). Some studies have been made to develop/integrate mobile services into existing LMS platforms. In an examination of expectations for an LMS, where both students and faculty responded, some differences of opinion emerged. Students expressed a stronger interest in accessing grades, feedback, assignment descriptions, course contents and announcements, while faculty was more interested in discussion features and real-time chat. Females in general also showed more interest in communication features than did males. Overall, students showed a higher level of appreciation for mobile features than did faculty (Antonenko et al. 2013). These results somewhat contrast those of an earlier study (Koole et al. 2010), where students, on the one hand, reported flexible access to the LMS as being important, but on the other hand rated mobile access low. Usability indicators show that the mobile interface was more difficult to navigate and enter data into compared to the computer interface, indicating that mobile usability was not well developed at this time. This is likely to have negatively affected student perceptions about using mobile access.

\section{Obstacles or problems with applications of BYOD to blur time and place}

In general, authors are more prone to discuss advantages and positive results, but some have highlighted challenges or problems with applications of BYOD. 
The more common themes that could be distinguished are presented under the following headlines.

\subsection{Podcasting not as mobile as expected}

The assumption that podcasts are suitable for opportunistic learning - that one can learn efficiently or conveniently with a podcast while doing other things sees little to no support in these studies. One likely reason for this is the cognitive load that active listening demand (Brown 2011; Morris 2010). Students prefer quiet locations, with easy access to their notes and relevant literature, usually listening via a stationary computer (e.g. Kazlauskas and Robinson 2012; Pearce and Scutter 2010; Popova et al. 2014). This is an argument against podcasts as an application for the blurring of the place of use. This is somewhat contradicted by Rosell-Aguilar (2015) in a study on iTunes U users, where a majority preferred to listen via mobile devices. This study, however, did not specifically target higher education but rather sampled iTunes $U$ users regardless of their purposes for using the service. This likely affected the outcome.

\subsection{Device challenges}

The mobility of small devices comes with certain trade-offs. The portable sizes lead to small screens that can be difficult to navigate and read (Boyinbode et al. 2013; Zawacki-Richter et al. 2009). Keyboards, whether physical or virtual, are small and are not as convenient for text production as are full sized keyboards, and apps do not always work as well as anticipated (Gikas and Grant 2013). Such restrictions put boundaries on learners' use of mobile devices, as:

although mobile devices and MOOCs do allow anytime and anywhere access, the fact that mobile devices have limitations to content interpretation and content creation, the ubiquity of mobile learning and the immediacy of learner interactions is affected by the limitations of the current mobile technology. (de Waard et al. 2012, p. 43)

Studies later in the review period did not mention device usability as frequently, likely due to devices becoming easier to use with every new device generation (larger and sharper screens, faster, etc.), thus indicating that this problem will become less pronounced over time. A student's familiarity with a device is another factor that can compensate such device usability issues (Boyinbode et al. 2013). Smartphones will likely not - within a foreseeable future - become as well suited for text production as computers with full sized keyboards, but the difference in usability does seem to decrease over time.

\subsection{Costs}

A prerequisite for BYOD activities is that students have mobile devices and that they can afford to use them for the intended purposes. Many reports on 
student device ownership show smartphone adoption rates well above $90 \%$ (e.g. Allagui 2014; Bradley and Holley 2011; Brett 2011; Cassidy et al. 2014; Meyer et al. 2015), but this is not universal. Bogdanović et al. (2014) reported that less than $50 \%$ of their sample owned smartphones, which became a barrier for the delivery of mobile activities. Even with ubiquitous mobile phone ownership, the costs of mobile services such as SMS can be an issue that inhibits interaction for students, especially for students without contracts (Brett 2011; McClean et al. 2010; Ng'ambi and Lombe 2012). Internet access can also be a cost-related issue where students do not have free data plans, or where such plans are not available, particularly when large files needs to be downloaded, such as podcasts or videos (Bogdanović et al. 2014; de Waard et al. 2012; Ng'ambi and Lombe 2012). These observations are reported from Europe as well as Africa.

\subsection{Digital native misconception - unexpected lack of ability}

Mark Prensky's theory of digital natives and digital immigrants suggests that teachers, as digital immigrants, need to adapt to digital natives expectations for them to learn to their full extent (Prensky 2001). This, for instance, involves utilizing students' mobile devices and creating non-text representations of learning material. Some studies, however, reported on students having technical difficulties due to faculty's overrating students' abilities and not providing enough support (Morris 2010; Vogt et al. 2010). It is also problematic to assume the opposite about older students "who may in fact be keen to take advantage of learning and teaching innovation" (Chester et al. 2011, p. 244). Benefits of the blurring of time and place boundaries, such as taking advantage of time snippets on the go for learning, are not self-evident to students to the extent that faculty sometimes assumes.

\subsection{Improper blurring of public and private}

The use of social media that are open to the general public can be problematic. As educational institutions cannot control public social media tools such as Twitter, abusive or inappropriate student behaviour can become problematic. When students use their private Twitter accounts for coursework, communication of a private nature might interfere with class communication, although this can be partly overcome by the proper use of hashtags (Lowe and Laffey 2011). The opposite situation also needs consideration, where the public sphere invades private life. Some students express a desire to distinguish their private lives from their public or professional lives, leading to difficulties incorporating the use of social networking sites such as Facebook for school related work. As one student expressed:

While on [...] our Facebook group, we have lecturers as 'friends.' I am uncomfortable with their presence because Facebook is my private life. Just as I would not have a drink with my supervisor, I don't want them to know about my private life. (Rambe 2013, p. 324) 
Complexities of identity management exist in public spaces and cannot be ignored. Such problems can hinder faculty from implementing social media solutions for the blurring of boundaries of time and space (Lowe and Laffey 2011; Rambe 2012, 2013).

\subsection{Device as a distraction}

The blurring of boundaries between formal and informal learning contexts is presented as a positive effect of mobile learning practices. However, students may become distracted by non-learning material when the device is supposed to be used for learning (Abu-Al-Aish et al. 2013), and the "alternation of informal conversations with academic engagements constitutes distractions that may jeopardise the smooth flow of the scholarly interactions" (Rambe 2012, p. 60 ). The distractive qualities of mobile devices were not directly examined in the articles in this review. However, from this review, it appears to be more of a faculty preconception than an observed problem. Students acknowledged the risk, but reports being able to separate private and educational use, and "students perceived the effectiveness of Facebook for communication more positively than the instructors" (Gikas and Grant 2013, p. 20).

\section{Conclusions}

This paper has reviewed journal articles published in the years of 2009 through 2015 that discussed applications of BYOD in higher education to blur the boundaries of time and place. Due to the large variation in publications per year, and the large variation between the publication year and the year of data collection, trend analysis becomes uncertain. A complication is that many articles lack information about the time of data collection. From the $53 \%$ of the articles that has a stated year of data collection, it is evident that the year of publication and the year of data collection can vary a lot. In some cases, data were collected the same year as the article was published, but in some cases, data were collected as much as six years prior to publication. The rapid technological development in the field of mobile devices can substantially change the conditions for research in just a few years time. This is a discrepancy worth taking into consideration when examining research in a field where conditions change rapidly due to technological development.

It seems likely that the trend is an increasing number of articles being published, as indicated by the regression analysis, but it cannot be determined with certainty due to the large yearly variation. What is clear, however, is that the number of different digital media and applications that are being discussed increases year over year. Earlier applications remain of interest while newer applications are being added to the researchers' palette. Podcasting, blogging, LMS and text messaging and instant messaging were examined during all of the reviewed years. Articles on social networking such as Facebook and Twitter started to appear in 2010, wikis in 2011, and AR saw one mention in 2013 but did not take off until 2015, together with 3-D. Research on social networking 
has increased, as is evident in Table 3, and so has the number of articles discussing constructivist- and sociocultural perspectives on learning over time (Table 4). It is very likely that these trends are related, i.e. that constructivist and socio-cultural perspectives on learning are better met by social networking technologies. Applications of direct instruction decrease, but are still prevalent. A possible part of the explanation for these shifts could be that newer tablets and smartphones afford social networking and diverse forms of communication better than what older mobile devices such as feature phones can, thus allowing more varied instructional models.

A closely related trend is that research becomes less about specific devices and more about which learning opportunities can be unfolded with ubiquitous access. Some earlier studies dealt with the development of platform-specific solutions to enable mobile access. In later studies, mobile access is more or less taken for granted, brands and types of devices are of lesser interest, and the focus of study has shifted more towards what can be done to support learning. Device usability has improved over time. Many observed problems in studies from the earlier part of the examined period are lacking from later studies, e.g. the experiment with a mobile access add-on for Moodle by Koole et al. (2010) compared with Shin and Kang (2015). This is likely due in part to larger and better quality displays, improved user interfaces in web services and apps, and better quality data connections. When device usability improves, the research focus seems to shift away from device limitations, towards activities and learning opportunities.

Experiments with virtual reality (VR) and AR are showing up in the last year being examined. This, together with the popularity of the AR game Pokémon Go (Niantic, Inc. 2016) in mid-2016, a good chance exists that various applications of AR for learning purposes will see increased interest from researchers in the near future.

Little to no support for Prensky's digital native theory exists in these studies. Rather, there are other factors besides age that is of relevance for determining whether the implementation of mobile learning will be successful. Also, assuming that younger students are digital natives are more likely to cause problems than to help, such as failing to provide adequate support due to false expectations.

There is a motive for further research on learning outcomes that employs experimental design, as there is a lack of rigorous research on the effects of applications of BYOD in higher education. Another area that should benefit from experimental research designs is the assumed distractive nature of mobile devices. This review reveals mixed results, where faculty perceptions indicate a potential problem, but where student perceptions are that the assumed distractions are manageable. Indications also exist that the instructional designs of the learning activities are important for the outcome.

\section{Compliance with ethical standards}

Conflict of interest The author declares that he has no conflict of interest. 


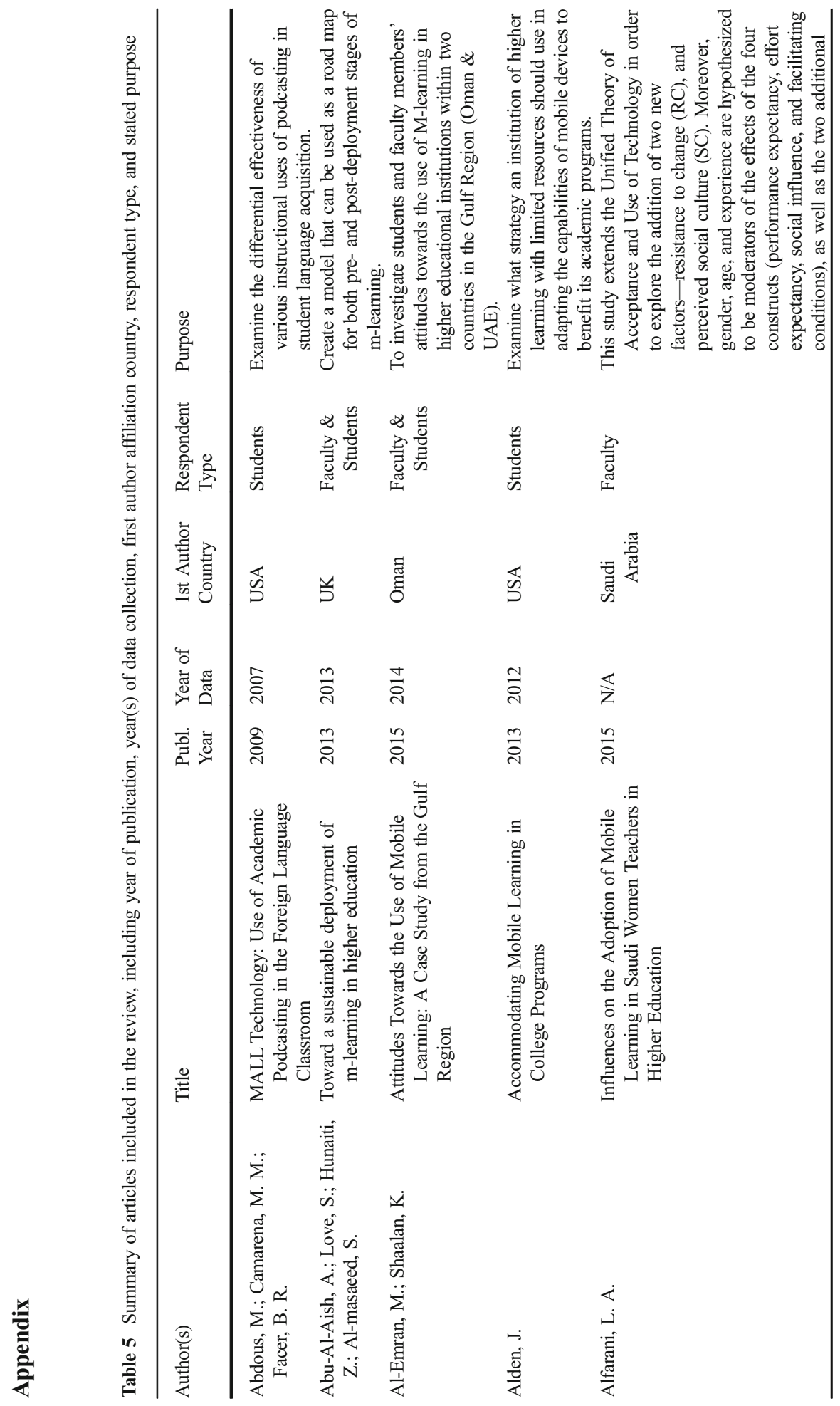




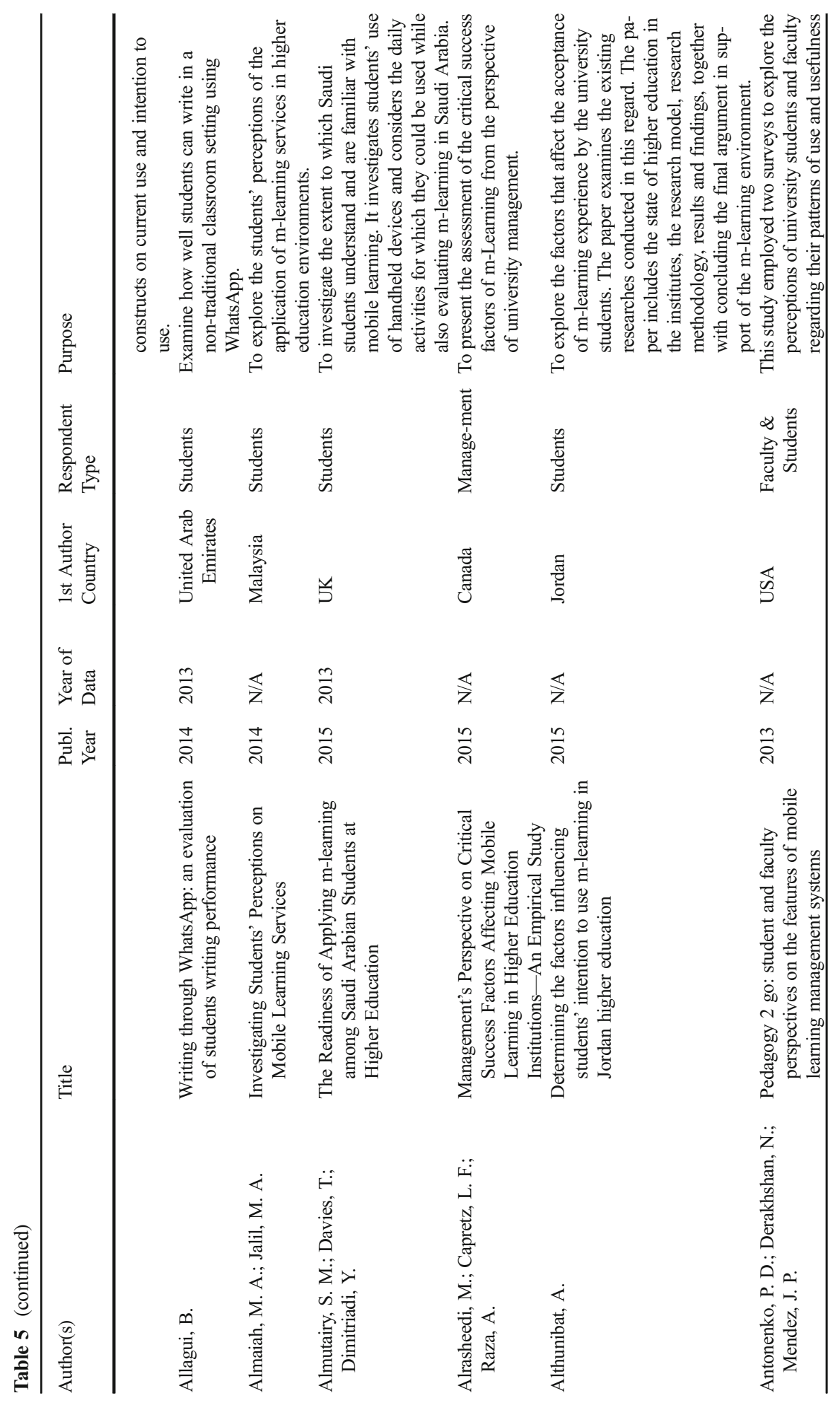




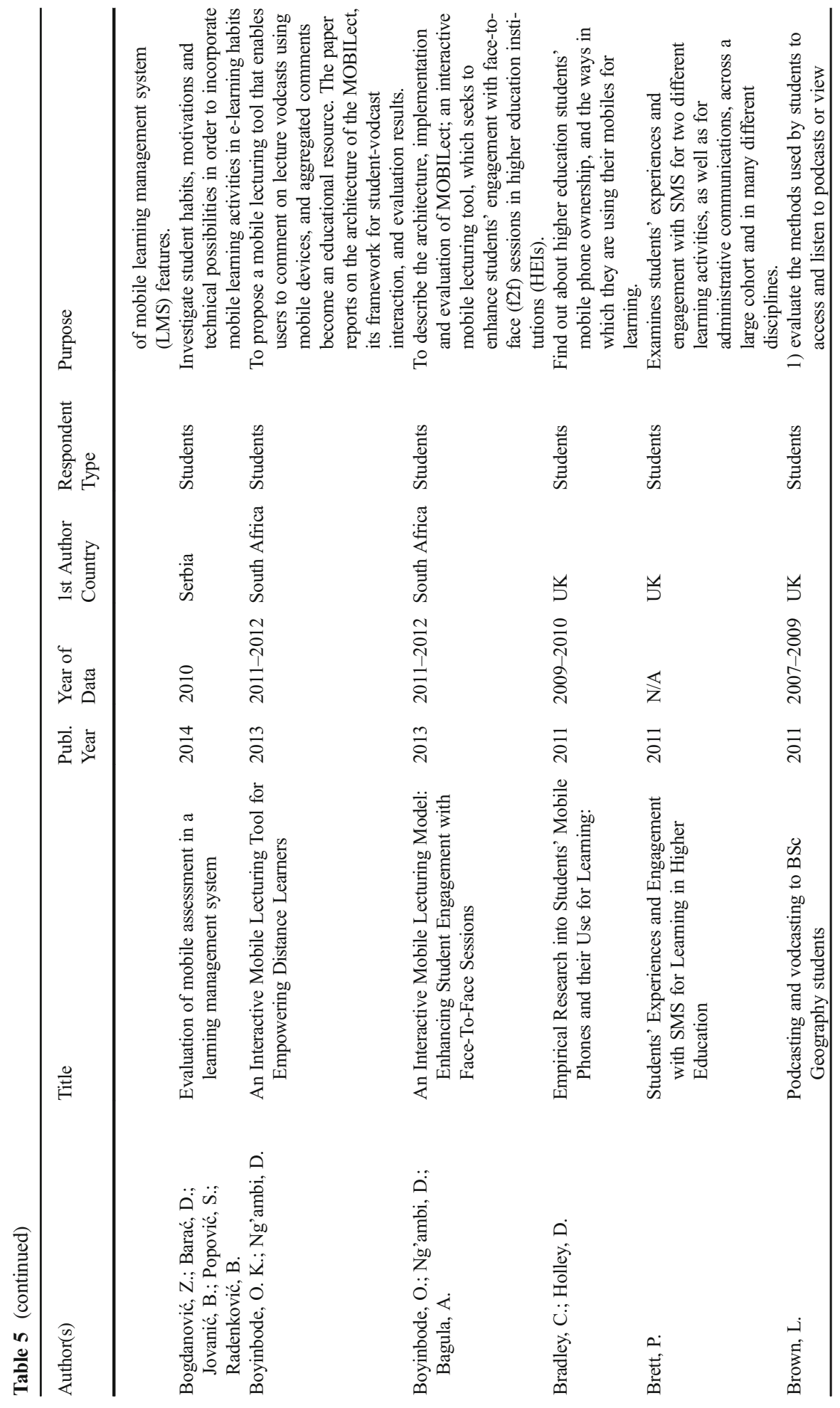




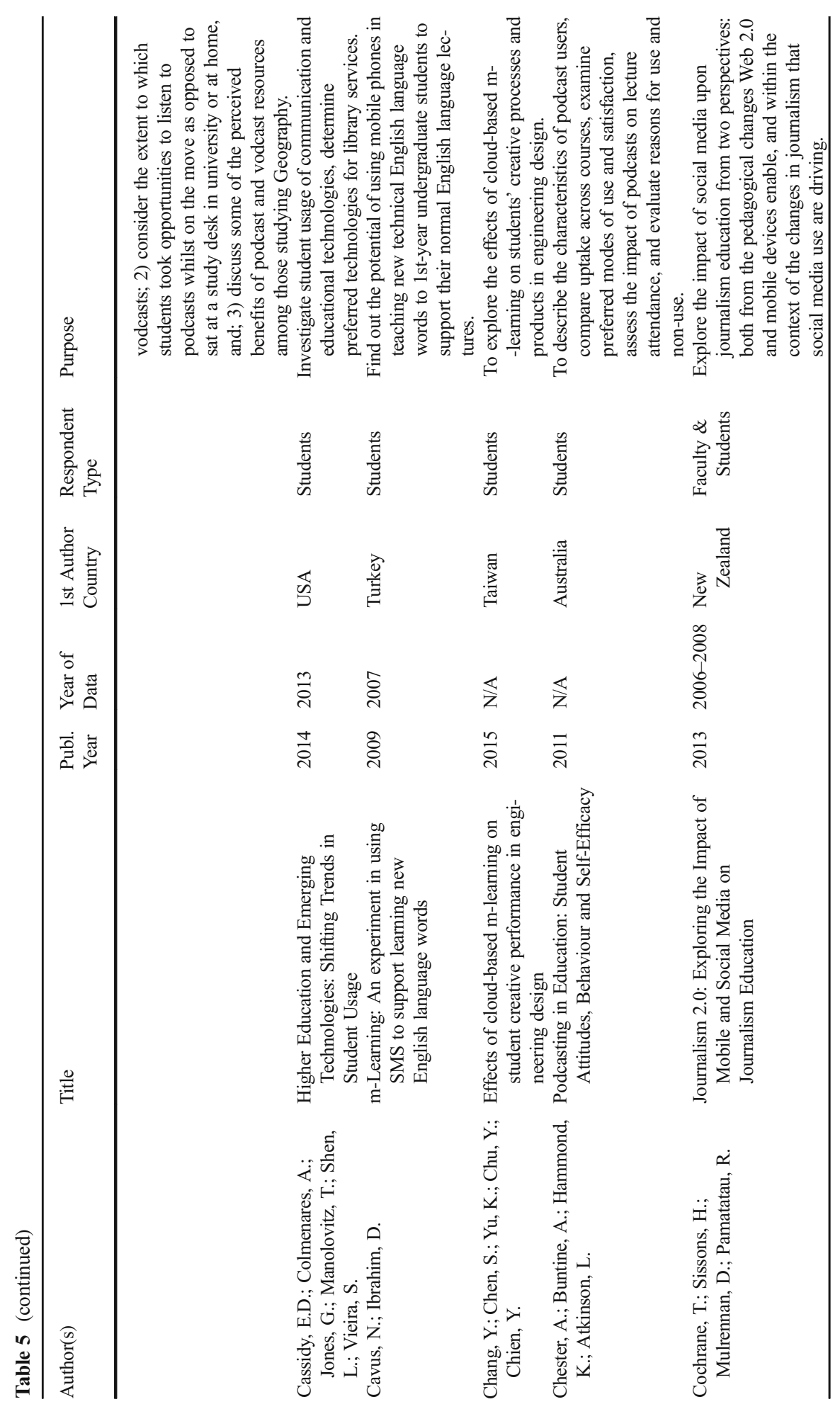




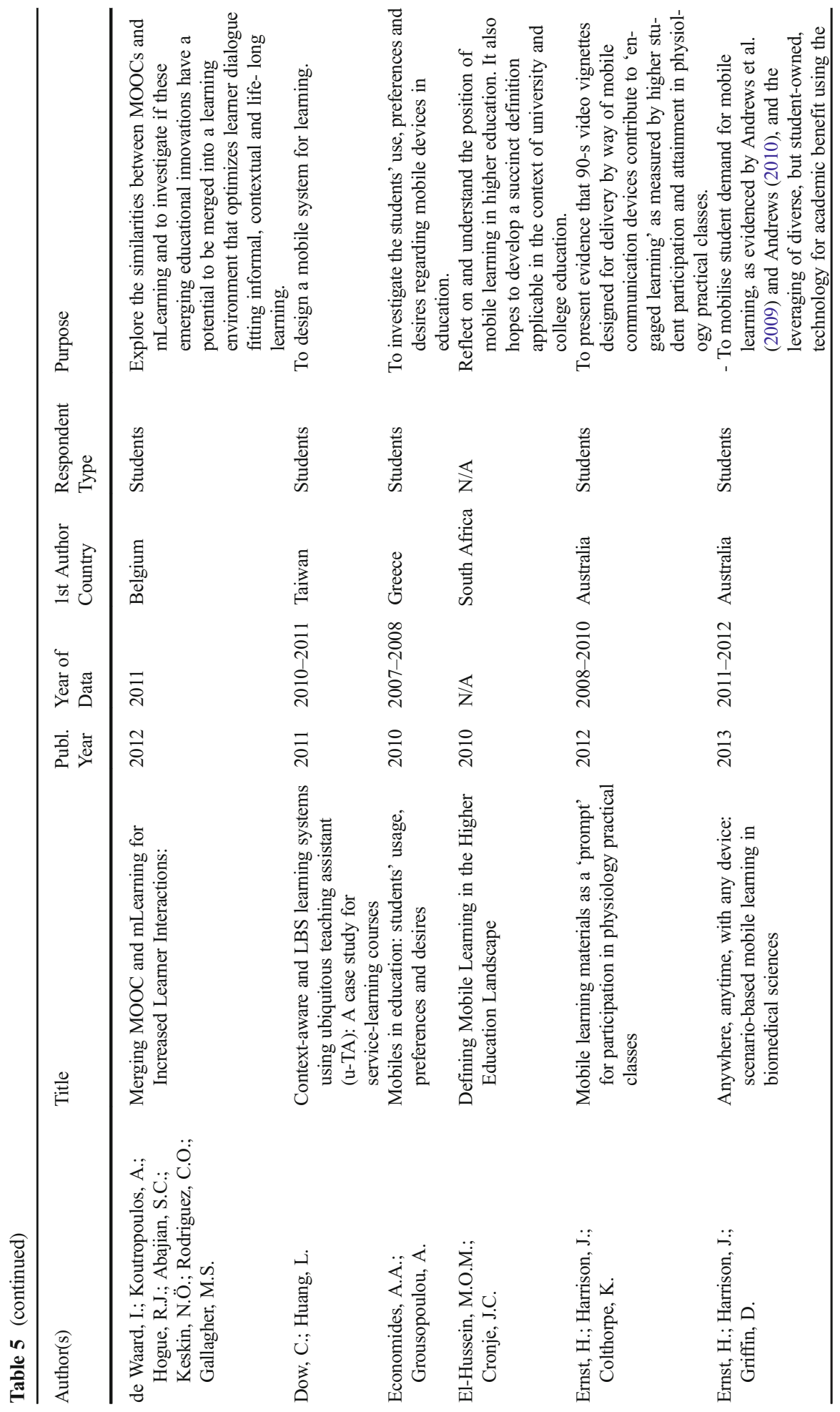




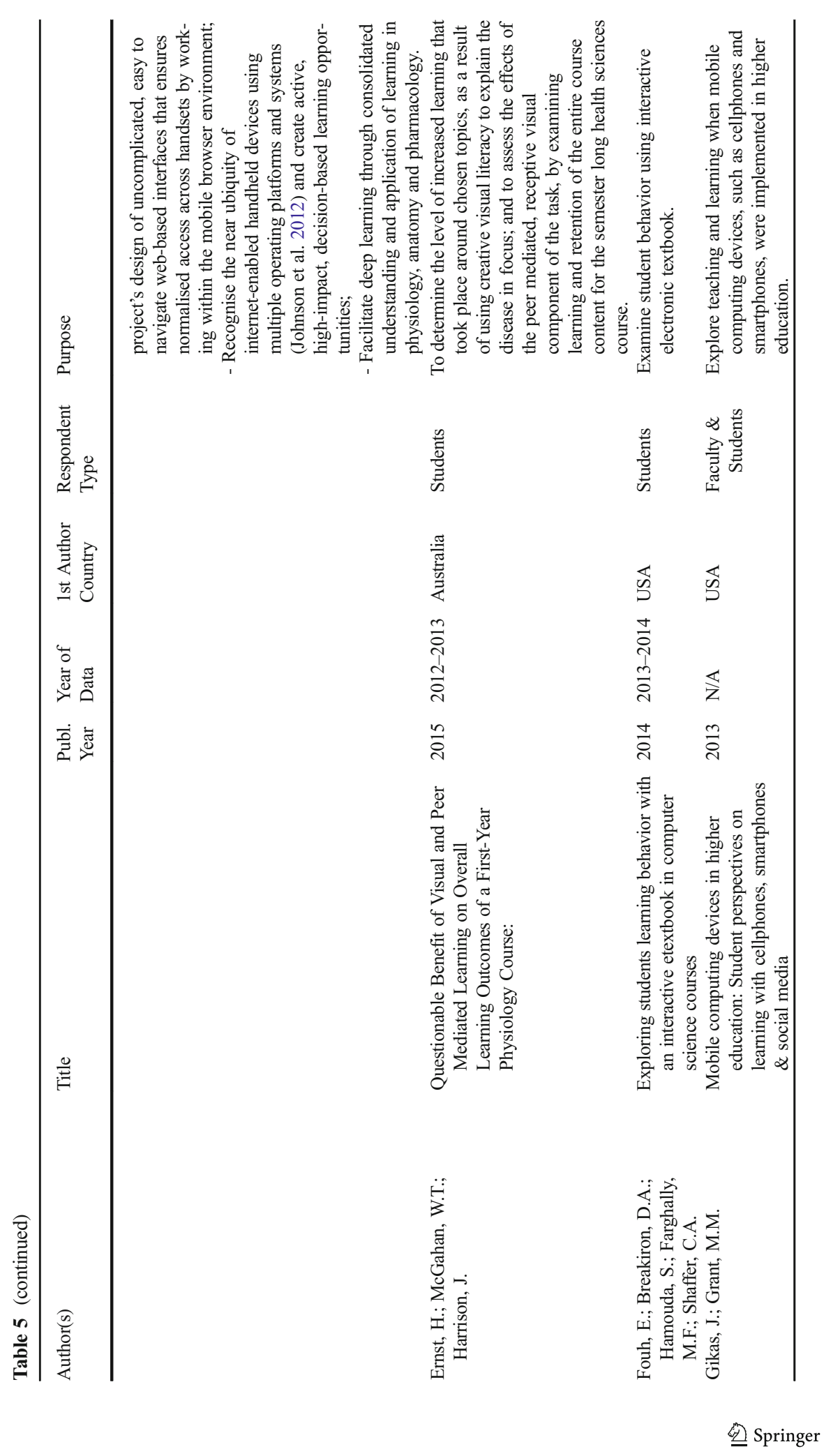




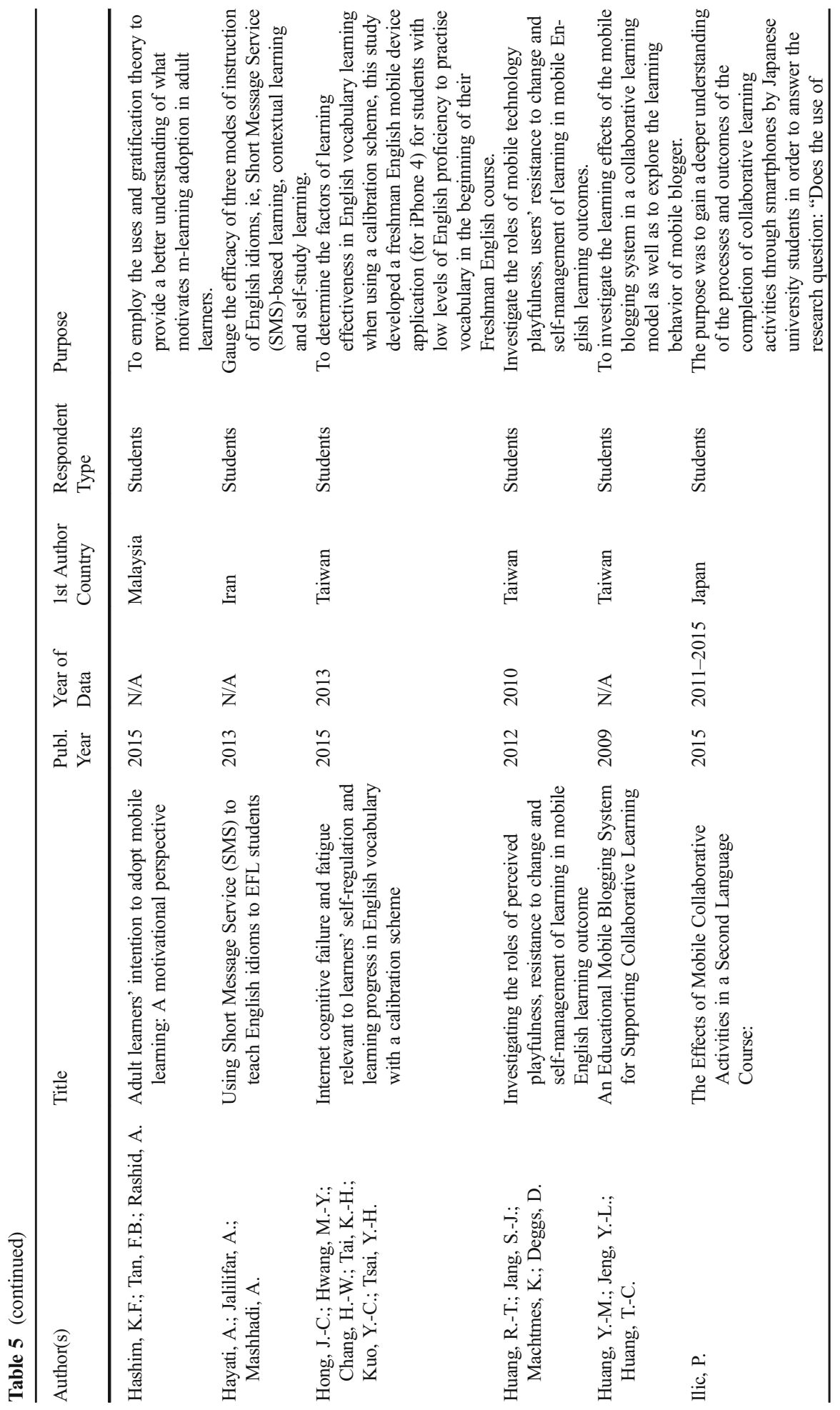




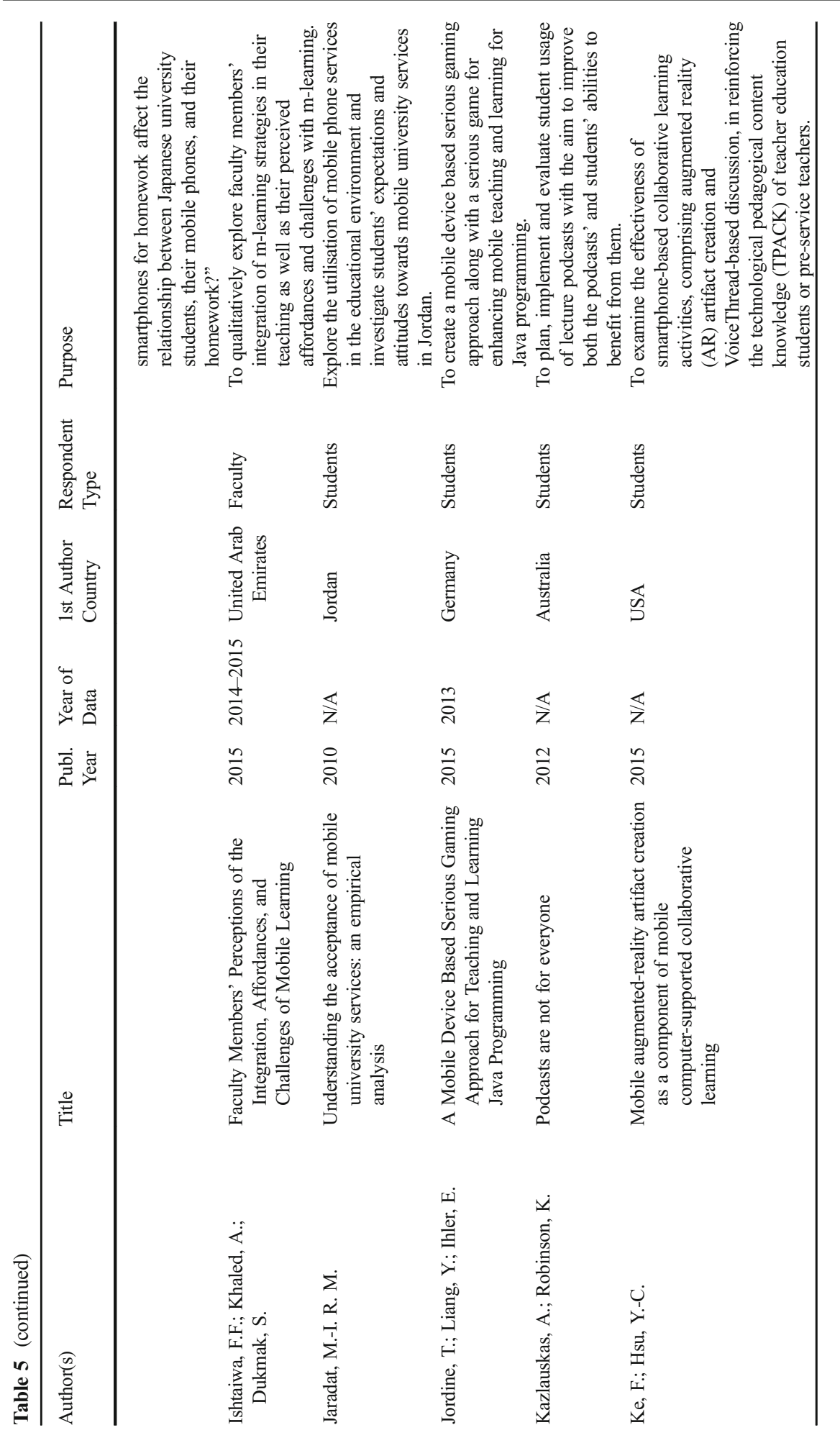




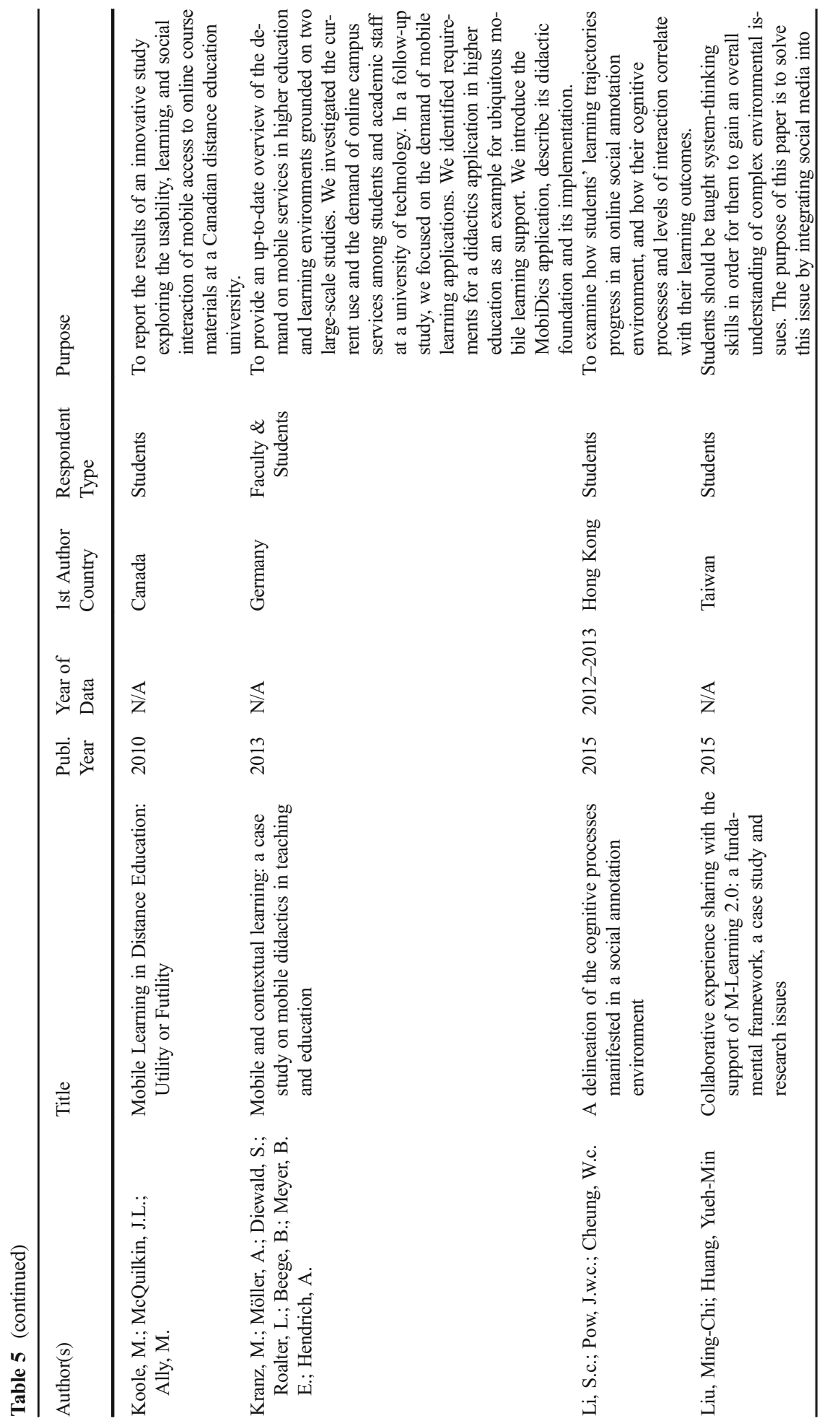




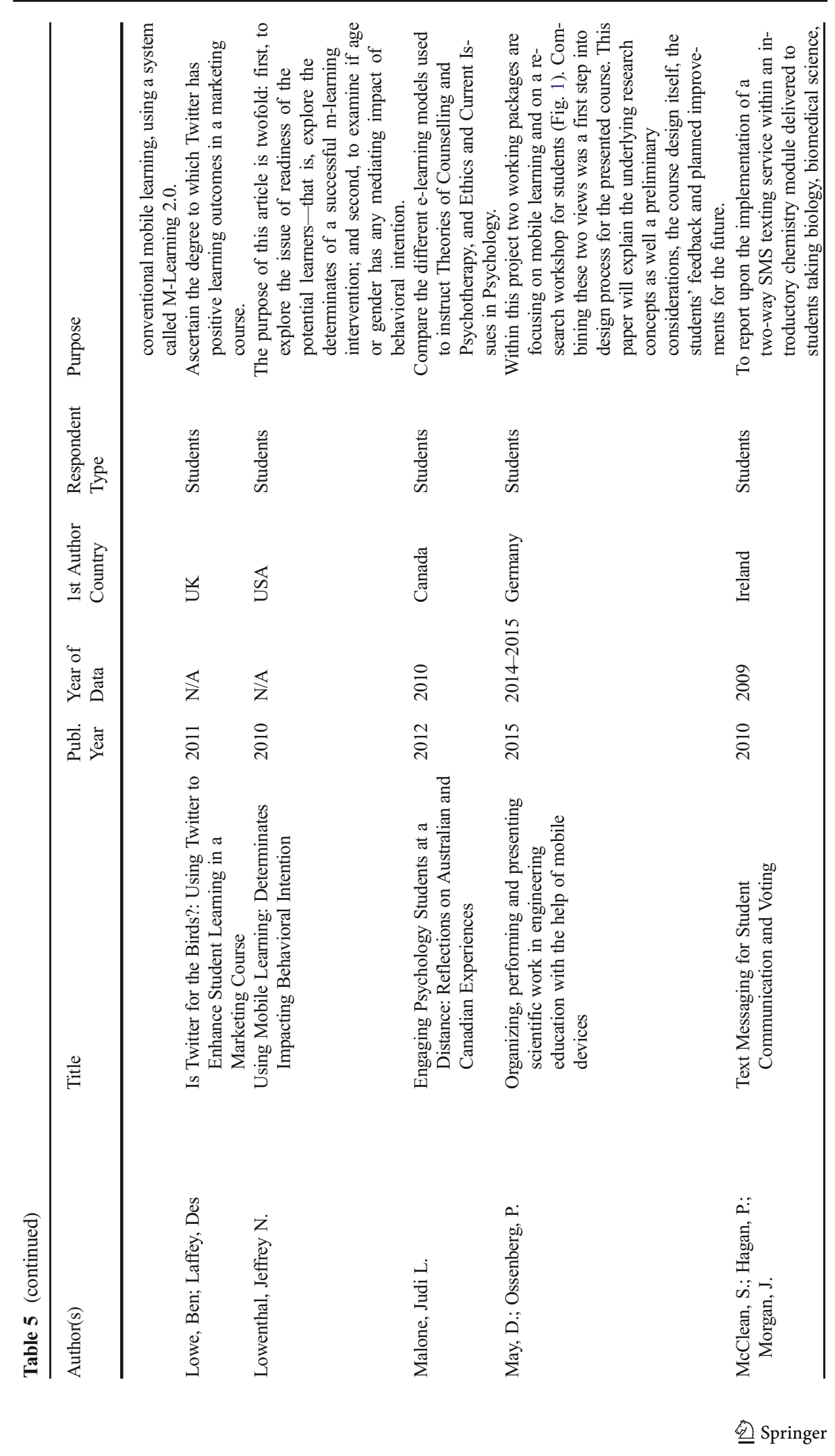




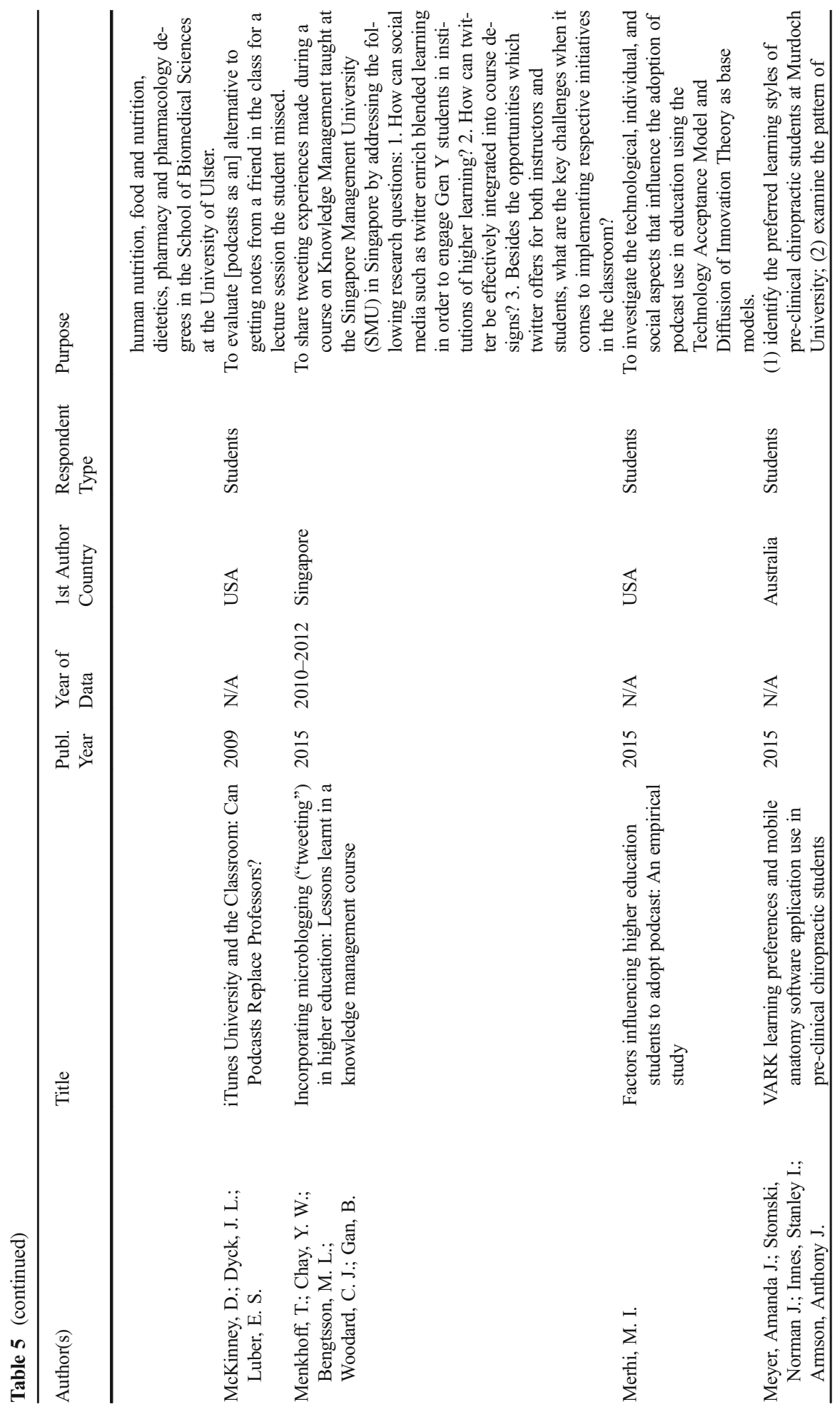




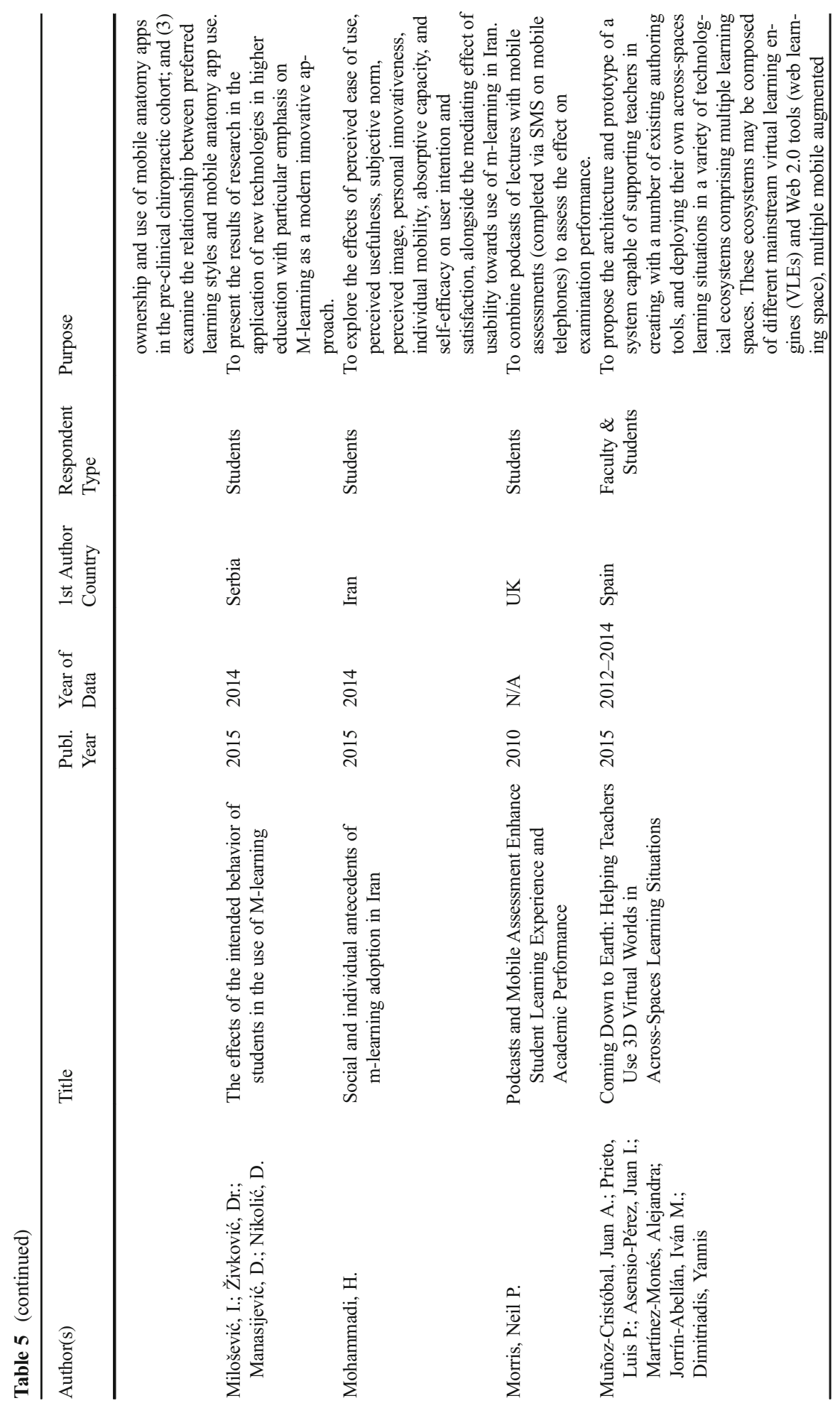




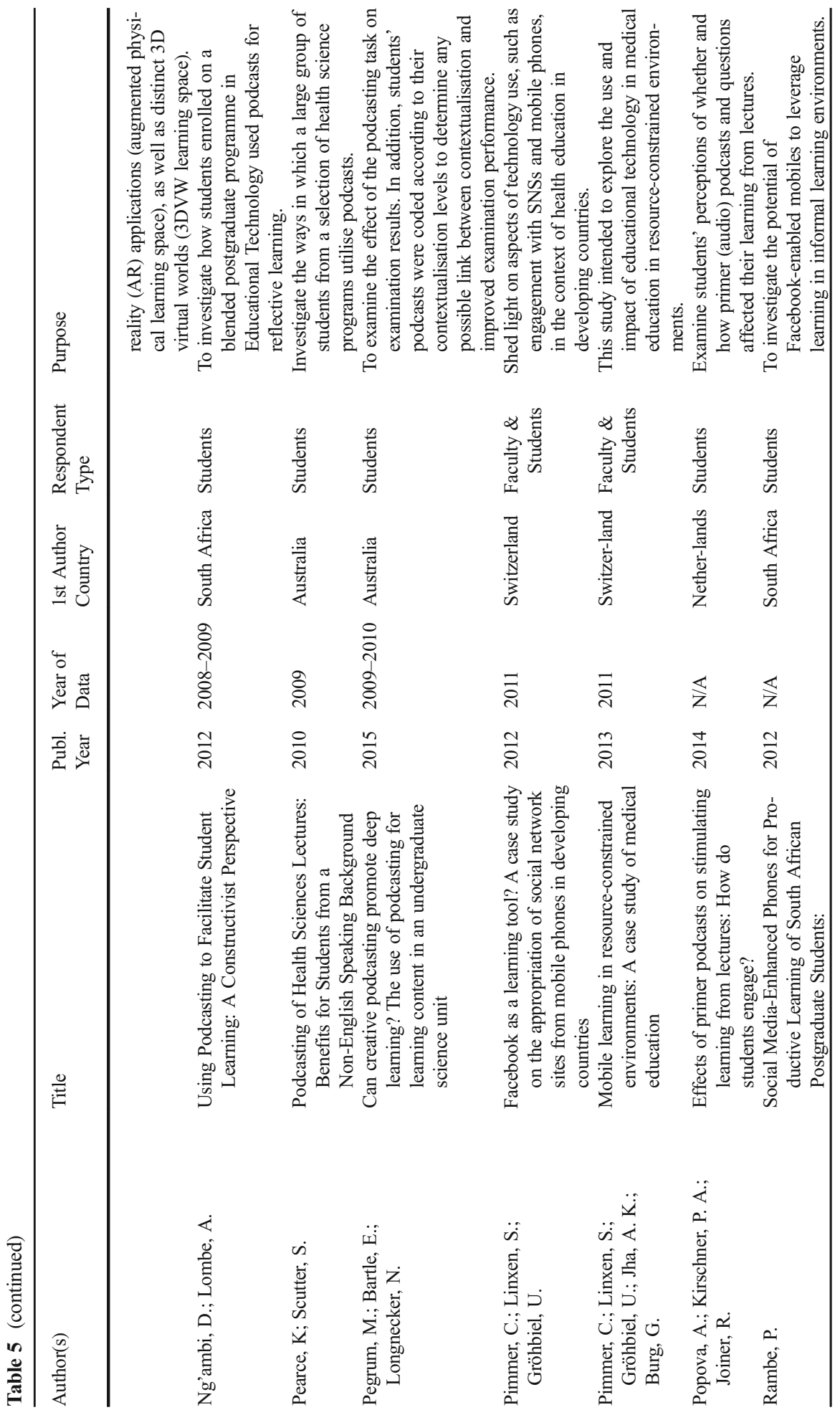




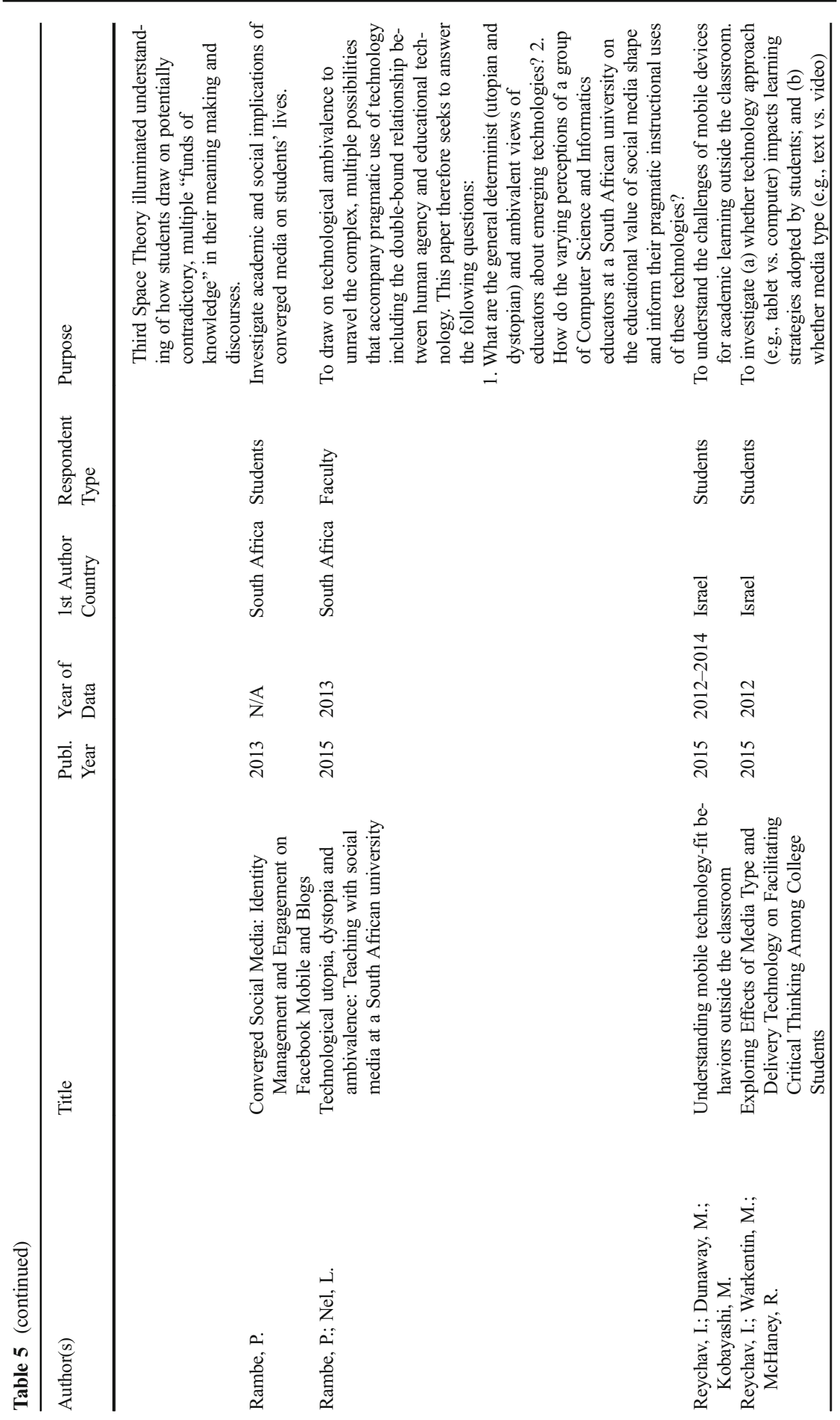




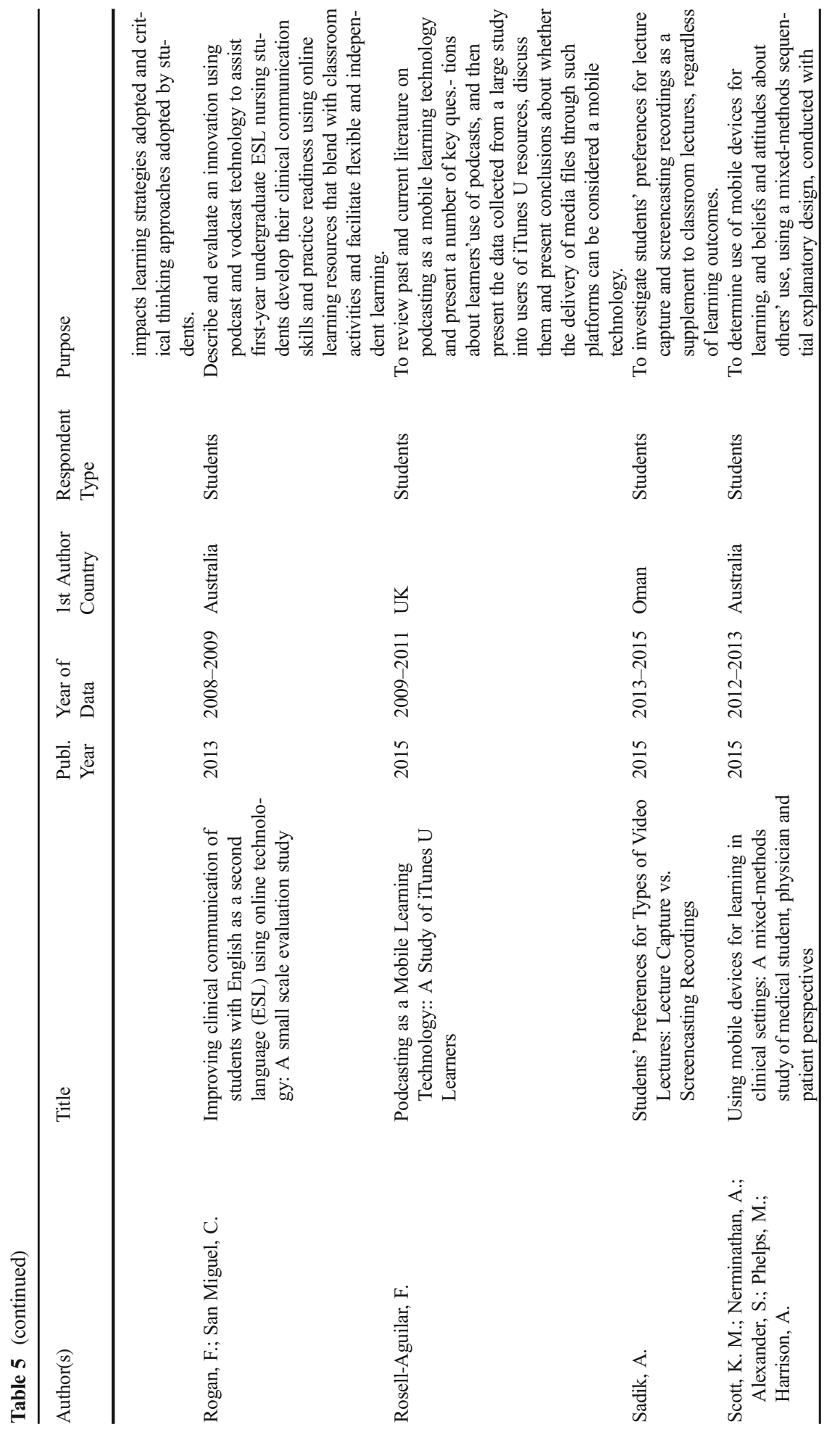




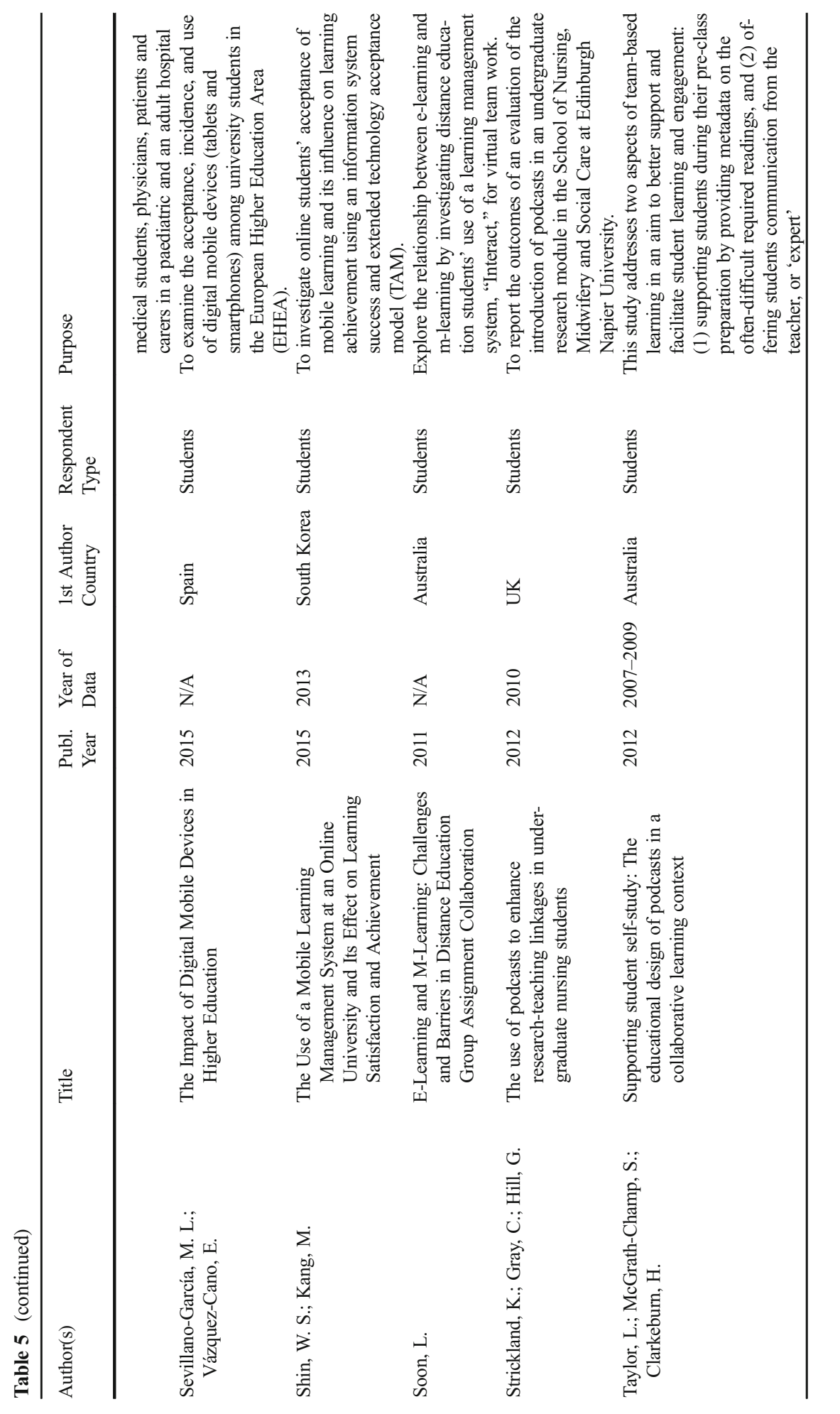




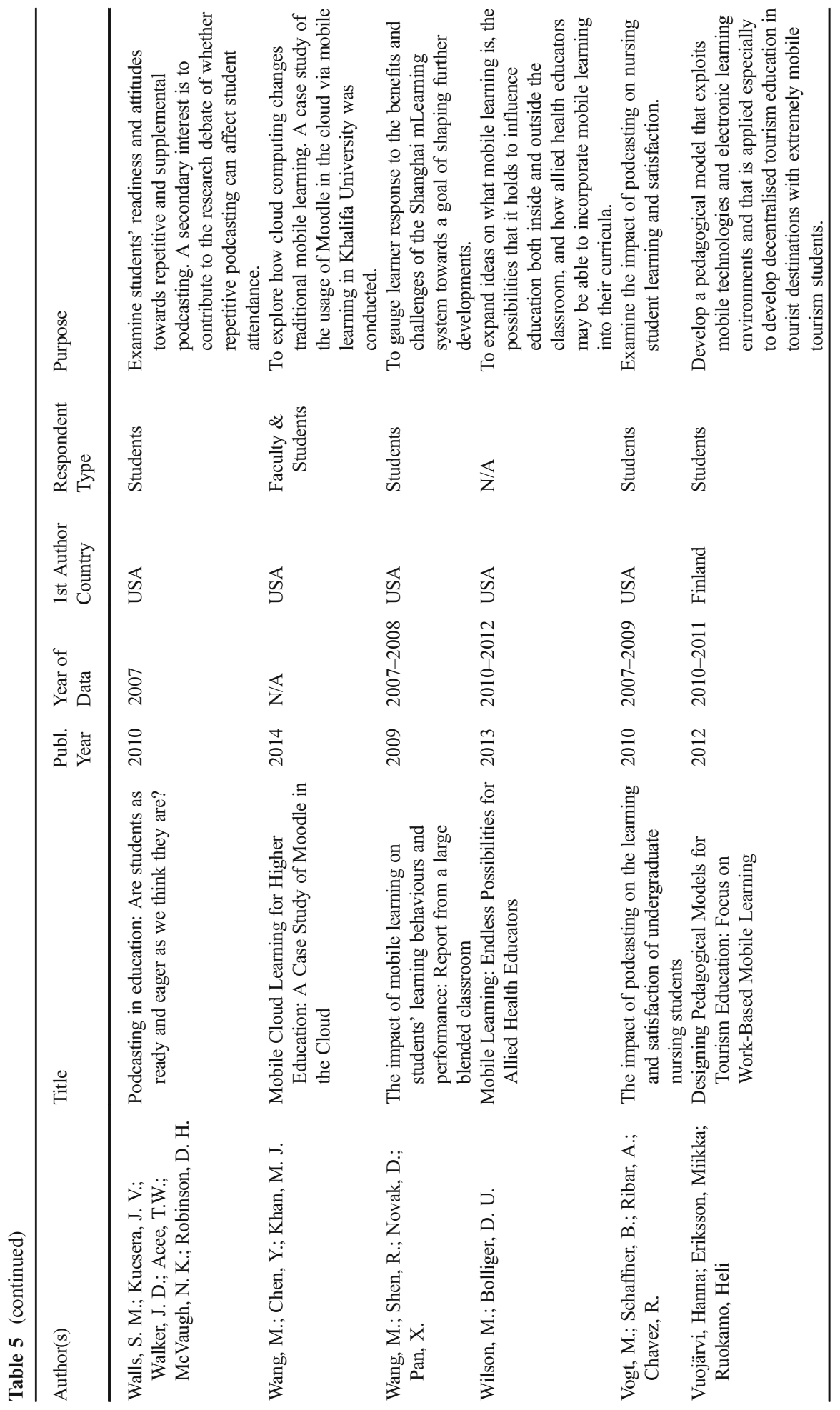




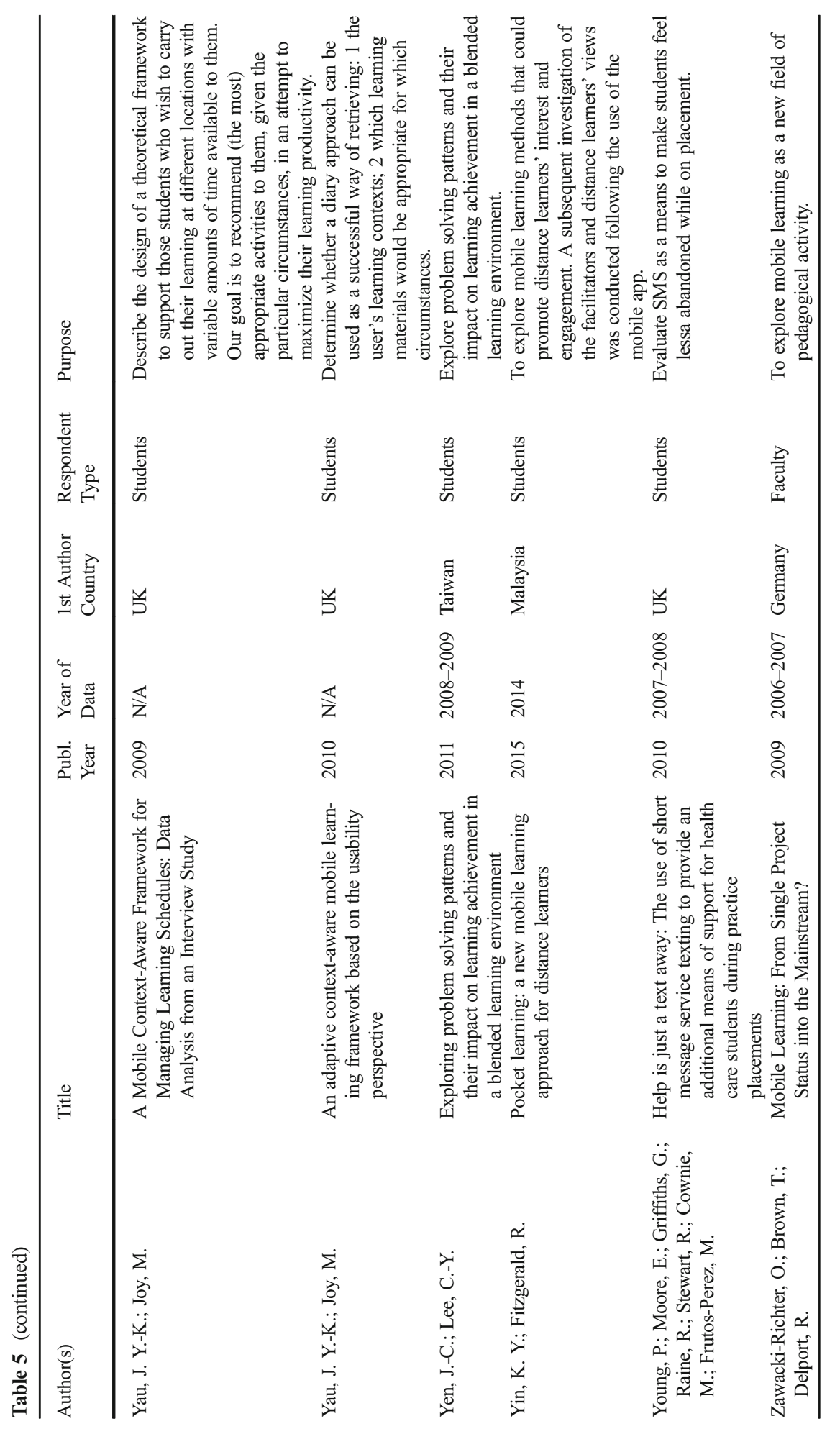


Open Access This article is distributed under the terms of the Creative Commons Attribution 4.0 International License (http://creativecommons.org/licenses/by/4.0/), which permits unrestricted use, distribution, and reproduction in any medium, provided you give appropriate credit to the original author(s) and the source, provide a link to the Creative Commons license, and indicate if changes were made.

\section{References}

Abu-Al-Aish, A., Love, S., Hunaiti, Z., \& Al-Masaeed, S. (2013). Toward a sustainable deployment of mlearning in higher education. International Journal of Mobile Learning and Organisation, 7(3), 253-276. doi:10.1504/IJMLO.2013.057165.

Allagui, B. (2014). Writing through WhatsApp: an evaluation of students writing performance. International Journal of Mobile Learning and Organisation, 8(3), 216-231. doi:10.1504/IJMLO.2014.067022.

Andrews, T. (2010) Developing a whole of university approach to adopting hand held student response tools. in Montobello, M., Camilleri, V. and Dingli, A. (Eds) mLearn2010: 9th World Conference on Mobile and Contextual Learning, Valetta, Malta, 19-21 October 2010.

Andrews, T., Davidson, B., Hill, A., Sloane, D. and Woodhouse, L. (2009). Linking different learning contexts through the use of mobile technologies to enhance competency. In: 8th World Congress on Mobile and Contextual Learning, Orlando, FL, 26-30 October 2009.

Antonenko, P. D., Derakhshan, N., \& Mendez, J. P. (2013). Pedagogy 2 go: student and faculty perspectives on the features of mobile learning management systems. International Journal of Mobile Learning and Organisation, 7(3), 197-209. doi:10.1504/IJMLO.2013.057161.

Atlas.Ti. (2015). ATLAS.ti Scientific Software Development GmbH.

Berge, Z. L., \& Muilenburg, L. Y. (Eds.). (2013). Handbook of mobile learning. New York: Routledge.

Bogdanović, Z., Barać, D., Jovanić, B., Popović, S., \& Radenković, B. (2014). Evaluation of mobile assessment in a learning management system. British Journal of Educational Technology, 45(2), 231244. doi:10.1111/bjet.12015.

Boyinbode, O., \& Ng'ambi, D. (2015). MOBILect: an interactive mobile lecturing tool for fostering deep learning. International Journal of Mobile Learning and Organisation, 9(2), 182-200. doi:10.1504 /IJMLO.2015.070706.

Boyinbode, O., Ng'ambi, D., \& Bagula, A. (2013). An interactive mobile lecturing model: enhancing student engagement with face-to-face sessions. International Journal of Mobile and Blended Learning, 5(2), 121. doi:10.4018/jmbl.2013040101.

Bradley, C., \& Holley, D. (2011). Empirical research into students' mobile phones and their use for learning. International Journal of Mobile and Blended Learning, 3(4), 38-53. doi:10.4018/jmbl.2011100103.

Brett, P. (2011). Students' experiences and engagement with SMS for learning in higher education. Innovations in Education and Teaching International, 48(2), 137-147.

Brown, L. (2011). Podcasting and vodcasting to BSc geography students. Planet, 24(1), 62-67. doi:10.11120 /plan.2011.00240062.

Cassidy, E. D., Colmenares, A., Jones, G., Manolovitz, T., Shen, L., \& Vieira, S. (2014). Higher education and emerging technologies: shifting trends in student usage. The Journal of Academic Librarianship, 40(2), 124-133. doi:10.1016/j.acalib.2014.02.003.

Caudill, J. G. (2007). The growth of m-learning and the growth of mobile computing: parallel developments. International Review of Research in Open and Distance Learning, 8(2). doi:10.19173/irrodl.v8i2.348.

Cavus, N., \& Ibrahim, D. (2009). M-learning: an experiment in using SMS to support learning new English language words. British Journal of Educational Technology, 40(1), 78-91. doi:10.1111/j.14678535.2007.00801.x.

Chayko, M. (2008). Portable communities: the social dynamics of online and mobile connectedness. Albany: SUNY Press.

Chester, A., Buntine, A., Hammond, K., \& Atkinson, L. (2011). Podcasting in education: student attitudes, behaviour and self-efficacy. Journal of Educational Technology \& Society, 14(2), 236-247.

Cochrane, T., Sissons, H., Mulrennan, D., \& Pamatatau, R. (2013). Journalism 2.0: exploring the impact of mobile and social media on journalism education. International Journal of Mobile and Blended Learning, 5(2), 22-38. doi:10.4018/jmb1.2013040102. 
de Waard, I., Koutropoulos, A., Hogue, R. J., Abajian, S. C., Keskin, N. Ö., Rodriguez, C. O., \& Gallagher, M. S. (2012). Merging. MOOC and mlearning for increased learner interactions: International Journal of Mobile and Blended Learning, 4(4), 34-46. doi:10.4018/jmbl.2012100103.

Dron, J., \& Anderson, T. (2014). Teaching crowds: learning and social media. Edmonton, AB: AU Press.

Ernst, H., Harrison, J., \& Colthorpe, K. (2012). Mobile learning materials as a "prompt" for participation in physiology practical classes. International Journal of Mobile Learning and Organisation, 6(1), 25-37. doi:10.1504/IJMLO.2012.046880.

Ernst, H., Harrison, J., \& Griffin, D. (2013). Anywhere, anytime, with any device: scenario-based mobile learning in biomedical sciences. International Journal of Mobile Learning and Organisation, 7(2), 99112. doi:10.1504/IJMLO.2013.055617.

Garrison, D. R. (2016). Thinking collaboratively: learning in a community of inquiry. New York: Routledge.

Garrison, D. R. (2017). E-learning in the twenty-first century: a community of inquiry framework for research and practice (Third ed.). New York: Routledge.

Garrison, D. R., Anderson, T., \& Archer, W. (1999). Critical inquiry in a text-based environment: computer conferencing in higher education. The Internet and Higher Education, 2(2-3), 87-105. doi:10.1016 /S1096-7516(00)00016-6.

Gikas, J., \& Grant, M. M. (2013). Mobile computing devices in higher education: student perspectives on learning with cellphones, smartphones \& social media. The Internet and Higher Education, 19, 18-26. doi:10.1016/j.iheduc.2013.06.002.

Grønli, T. M., Hansen, J., Ghinea, G., \& Younas, M. (2014). Mobile Application Platform Heterogeneity: Android vs Windows Phone vs iOS vs Firefox OS. In 2014 I.E. 28th International Conference on Advanced Information Networking and Applications (pp. 635-641). Presented at the 2014 I.E. 28th International Conference on Advanced Information Networking and Applications. doi:10.1109 /AINA.2014.78

Hayati, A., Jalilifar, A., \& Mashhadi, A. (2013). Using short message service (SMS) to teach English idioms to EFL students. British Journal of Educational Technology, 44(1), 66-81. doi:10.1111/j.14678535.2011.01260.x.

Hedin, B. (2014). Exploring opportunistic use of mobile devices for studying in higher education (doctoral dissertation). Stockholm, Sweden: Royal Institute of Technology Retrieved from http://urn.kb. se/resolve?urn=urn:nbn:se:kth:diva-150389.

Hwang, G.-J., \& Tsai, C.-C. (2011). Research trends in mobile and ubiquitous learning: a review of publications in selected journals from 2001 to 2010. British Journal of Educational Technology, 42(4), E65-E70. doi:10.1111/j.1467-8535.2011.01183.x.

Ilic, P. (2015). The effects of mobile collaborative activities in a second language course. International Journal of Mobile and Blended Learning, 7(4), 16-37. doi:10.4018/IJMBL.2015100102.

Johnson, L., Adams, S. and Cummins, M. (2012) The NMC Horizon Report: 2012 Higher Education Edition, Austin, TX: The New Media Consortium.

Johnson, L., Adams Becker, S., Estrada, V., \& Freeman, A. (2015). NMC horizon report: 2015 Higher Education Edition. Austin, TX: The New Media Consortium.

Johnson, L., Adams Becker, S., Cummins, M., Estrada, V., Freeman, A., \& Hall, C. (2016). NMC horizon report: 2016 Higher Education Edition. Austin, TX: The New Media Consortium.

Kazlauskas, A., \& Robinson, K. (2012). Podcasts are not for everyone. British Journal of Educational Technology, 43(2), 321-330. doi:10.1111/j.1467-8535.2010.01164.x.

Keegan, D. (2005). The incorporation of mobile learning into mainstream education and training. In World Conference on Mobile Learning, Cape Town (pp. 1-11). http://www.mlearn.org/mlearn2005 /CD/papers/keegan1.pdf. Accessed 23 November 2015

Khaddage, F., Christensen, R., Lai, W., Knezek, G., Norris, C., \& Soloway, E. (2015). A model driven framework to address challenges in a mobile learning environment. Education and Information Technologies, 20(4), 625-640. doi:10.1007/s10639-015-9400-x.

Koole, M., McQuilkin, J. L., \& Ally, M. (2010). Mobile learning in distance education: utility or futility. Journal of Distance Education, 24(2), 59-82.

Lowe, B., \& Laffey, D. (2011). Is twitter for the birds?: using twitter to enhance student learning in a marketing course. Journal of Marketing Education, 33(2), 183-192. doi:10.1177/0273475311410851.

MacDonald, J., \& Creanor, L. (2010). Learning with online and mobile technologies: a student survival guide. In Farnham, surrey, England. Burlington, VT: Gower.

McClean, S., Hagan, P., \& Morgan, J. (2010). Text messaging for student communication and voting. Bioscience Education, 16(1), 1-12. doi:10.3108/beej.16.4.

McGarr, O. (2009). A review of podcasting in higher education: its influence on the traditional lecture. Australasian Journal of Educational Technology, 25(3), 309-321. 
Menkhoff, T., Chay, Y. W., Bengtsson, M. L., Woodard, C. J., \& Gan, B. (2015). Incorporating microblogging ("tweeting") in higher education: Lessons learnt in a knowledge management course. Computers in Human Behavior, 51, Part B, 1295-1302. doi:10.1016/j.chb.2014.11.063

Meyer, A. J., Stomski, N. J., Innes, S. I., \& Armson, A. J. (2015). VARK learning preferences and mobile anatomy software application use in pre-clinical chiropractic students. Anatomical Sciences Education, n/a-n/a. doi:10.1002/ase.1555.

Miller, C., \& Doering, A. H. (Eds.). (2014). The new landscape of mobile learning: redesigning education in an app-based world. New York: Routledge.

Morris, N. P. (2010). Podcasts and mobile assessment enhance student learning experience and academic performance. Bioscience Education, 16(1), 1-7. doi:10.3108/beej.16.1.

Ng'ambi, D., \& Lombe, A. (2012). Using podcasting to facilitate student learning: a constructivist perspective. Journal of Educational Technology \& Society, 15(4), 181-192.

Niantic, I. (2016). Pokémon GO. .http://www.itunes.apple.com

Pachler, N., Bachmair, B., \& Cook, J. (2010). Mobile learning - structures, agency, practices. New York: Springer. doi:10.1007/978-1-4419-0585-7.

Pearce, K., \& Scutter, S. (2010). Podcasting of health sciences lectures: benefits for students from a nonEnglish speaking background. Australasian Journal of Educational Technology, 26(7), 1028-1041.

Pegrum, M. (2014). Mobile learning: languages, literacies and cultures. In Houndmills, Basingstoke, Hampshire. New York: Palgrave Macmillan.

Pegrum, M., Bartle, E., \& Longnecker, N. (2015). Can creative podcasting promote deep learning? The use of podcasting for learning content in an undergraduate science unit. British Journal of Educational Technology, 46(1), 142-152. doi:10.1111/bjet.12133.

Pimmer, C., Linxen, S., \& Gröhbiel, U. (2012). Facebook as a learning tool? A case study on the appropriation of social network sites from mobile phones in developing countries. British Journal of Educational Technology, 43(5), 726-738. doi:10.1111/j.1467-8535.2012.01351.x.

Popova, A., Kirschner, P. A., \& Joiner, R. (2014). Effects of primer podcasts on stimulating learning from lectures: how do students engage? British Journal of Educational Technology, 45(2), 330-339. doi:10.1111/bjet.12023.

Prensky, M. (2001). Digital natives, digital immigrants. On the Horizon, 9(5), 1-6. doi:10.1108 /10748120110424816.

Rambe, P. (2012). Social media-enhanced phones for productive learning of. South African postgraduate students: International Journal of Mobile and Blended Learning, 4(2), 49-66. doi:10.4018 /jmbl.2012040104.

Rambe, P. (2013). Converged social media: identity management and engagement on Facebook mobile and blogs. Australasian Journal of Educational Technology, 29(3), 315-336.

Rosell-Aguilar, F. (2015). Podcasting as a mobile learning technology: a study of Itunes U learners. International Journal of Mobile and Blended Learning, 7(1), 41-60. doi:10.4018/ijmbl.2015010104.

Sadik, A. (2015). Students' preferences for types of video lectures: Lecture capture vs. screencasting recordings. International Journal of E-Learning \& Distance Education, 30(2). doi:10.5430/ijhe.v4n4p94

Shin, W. S., \& Kang, M. (2015). The use of a mobile learning management system at an online university and its effect on learning satisfaction and achievement. International Review of Research in Open and Distributed Learning, 16(3), 110-130.

Shippee, M., \& Keengwe, J. (2014). mLearning: anytime, anywhere learning transcending the boundaries of the educational box. Education and Information Technologies, 19(1), 103-113. doi:10.1007/s10639-012-9211-2.

Soon, L. (2011). E-learning and m-learning: challenges and barriers in distance education group assignment collaboration. International Journal of Mobile and Blended Learning, 3(3), 43-58. doi:10.4018 /jmbl.2011070104.

Sundgren, M., \& Jaldemark, J. (2016). Breaking the boundaries of space and time: a review of applications of bring-your-own-device in higher education (pp. 332-335). Presented at the Tenth International Conference on Networked Learning, Lancaster. Retrieved from http://www. networkedlearningconference.org.uk/abstracts/sundgren.htm

Thomas, D. R. (2006) A General Inductive Approach for Analyzing Qualitative Evaluation Data. American Journal of Evaluation, 27 (2):237-246

Traxler, J. (2007). Defining, discussing, and evaluating mobile learning: The moving finger writes and having writ.... International Review of Research in Open and Distance Learning, 8(2), 1-12.

Traxler, J., \& Kukulska-Hulme, A. (Eds.). (2016). Mobile learning: the next generation. New York: Routledge.

Vogt, M., Schaffner, B., Ribar, A., \& Chavez, R. (2010). The impact of podcasting on the learning and satisfaction of undergraduate nursing students. Nurse Education in Practice, 10(1), 38-42. doi:10.1016/j. nepr.2009.03.006. 
Vuojärvi, H., Eriksson, M., \& Ruokamo, H. (2012). Designing pedagogical models for tourism education: focus on work-based mobile learning. International Journal of Mobile and Blended Learning, 4(3), 5367. doi:10.4018/jmb1.2012070104.

Wickham, M., Dunn, A., \& Sweeney, S. (2012). Analysis of the leading tourism journals 1999-2008. Annals of Tourism Research, 39(3), 1714-1718. doi:10.1016/j.annals.2012.05.022.

Wiki. (2016, December 2). In Wikipedia. Retrieved from https://en.wikipedia.org/w/index.php?title= Wiki\&oldid=752613214

Wilson, M., \& Bolliger, D. U. (2013). Mobile learning: endless possibilities for allied health educators. Journal of Diagnostic Medical Sonography, 29(5), 220-224. doi:10.1177/8756479313503734.

Winters, N. (2006). What is mobile learning? In M. Sharples (Ed.), Big issues in mobile learning. LSRI: University of Nottingham http://citeseerx.ist.psu.edu/viewdoc/download?doi=10.1.1.465.7672\&rep=rep1 \&type=pdf. Accessed 8 February 2016.

Wu, W.-H., Jim Wu, Y.-C., Chen, C.-Y., Kao, H.-Y., Lin, C.-H., \& Huang, S.-H. (2012). Review of trends from mobile learning studies: a meta-analysis. Computers \& Education, 59(2), 817-827. doi:10.1016/j. compedu.2012.03.016.

Yin, K. Y., \& Fitzgerald, R. (2015). Pocket learning: a new mobile learning approach for distance learners. International Journal of Mobile Learning and Organisation, 9(3), 271-283. doi:10.1504 /IJMLO.2015.074215.

Young, P., Moore, E., Griffiths, G., Raine, R., Stewart, R., Cownie, M., \& Frutos-Perez, M. (2010). Help is just a text away: the use of short message service texting to provide an additional means of support for health care students during practice placements. Nurse Education Today, 30(2), 118-123. doi:10.1016/j. nedt.2009.06.010.

Zawacki-Richter, O., Brown, T., \& Delport, R. (2009). Mobile learning: from single project status into the mainstream? European Journal of Open, Distance and E-Learning, 12(1) 